\title{
BASE DRIFT AND THE LONGER RUN GROWTH OF. M1: EXPERIENCE FROM A DECADE OF MONETARY TARGETING
}

\author{
Alfred Broaddus and Marvin Goodfriend*
}

I.

\section{INTRODUCTION: THE NATURE OF BASE DRIFT}

This article discusses a technical aspect of the Federal Reserve's monetary targeting procedure that has come to be known as "base drift." The Fed has been announcing target ranges for the growth of M1 and other monetary aggregates since $1975 .{ }^{1}$ These ranges have been expressed in terms of rates of growth from a base quarter to the quarter four quarters later. ${ }^{2}$ The term "base drift", refers to the Fed's practice of using the actual dollar level of an

*The authors are both Vice President and Economist, Federal Reserve Bank of Richmond. Marvin Goodfriend is temporarily on leave from the Bank as a Senior Staff Economist with the President's Council of Economic Advisers. The authors wish to thank Sandra D. Baker, Associate Economist, for valuable research assistance.

${ }^{1} \mathrm{M} 1$ is the narrowly defined money supply. It currently includes (1) currency outside the Treasury, Federal Re serve Banks, and the vaults of commercial banks; (2) travelers checks of nonbank issuers; (3) demand deposits at all commercial banks other than those due to domestic banks, the U. S. government, and foreign banks and official institutions less cash items in the process of collection and Federal Reserve float; and (4) other checkable deposits (OCD) consisting of negotiable order of withdrawal (NOW) and automatic transfer service (ATS) accounts at depository institutions, credit union share draft accounts, and demand deposits at thrift institutions. The currency and demand deposit components exclude the estimated amount of vault cash and demand deposits respectively held. by thrift institutions to service their OCD liabilities.

${ }^{2}$ The Fed began announcing target ranges following the passage of House Concurrent Resolution 133 in March 1975. The first targets for each aggregate were expressed in terms of growth rates from March 1975 to March 1976. Subsequent targets were expressed as growth rates from a particular quarter to the quarter four quarters later. From 1975 through the end of 1978, a new four-quarter target was established in each successive quarter Since then, under the terms of the Humphrey-Hawkins Act of 1978, targets have generally been set only once a year. These targets extend from the fourth quarter of the base year to the fourth quarter of the current year. The one exception to this procedure since 1978 occurred in mid-1983 when a new target was set for the second half of the year. With this exception only the nonoverlapping fourth quarter-to-fourth quarter targets are considered in this article. aggregate in the base quarter as the base level for the target range, rather than the midpoint of the targeted range set in the preceding targeting period.

Figure 1 provides a hypothetical illustration. The figure assumes that the 6 percent midline of the 4 to 8 percent target range set for the growth rate of M1 at the beginning, of year 1 implies an M1 level of $\$ 500$ billion in the fourth quarter of the year. The actual growth of M1 in year 1, however, exceeds the target range, so that the actual level in the fourth quarter is $\$ 520$ billion. In this situation, the base level for the target range in year 2 is $\$ 520$ billion, and the amount of base drift is $\$ 20$ billion.

A long-standing objective of Fed monetary policy has been to reduce the longer run growth of M1 and the other monetary aggregates over time to noninflationary rates in order to restore price stability. ${ }^{3} \mathrm{To}$ date, however, relatively little progress has been made toward reducing the longer run growth of M1. Most

\footnotetext{
${ }^{3}$ The importance of this objective has been emphasized by all Federal Reserve Chairmen in recent years. For example, Chairman Burns made the following statement in testimony before the Banking and Currency Committee of the, House of Representatives on July 30, 1974:
}

A return to price stability will require a national commitment to fight inflation this year and in the years to come. Monetary policy must play a key role in this endeavor, and we, in the Federal Reserve, recognize that fact. We are determined to reduce, over time, the rate of monetary and credit expansion

to a pace consistent with price stability.

See Burns (1974), p. 258.

More recently, Chairman Volcker made the following statement before the Senate Committee on Banking, Housing, and Urban Affairs on February 25, 1981:

These technical considerations should not obscure the basic thrust of our policy posture. Our intent is not to accommodate inflationary forces; rather, we mean to exert continuing, restraint on growth in money and credit to squeeze out inflationary pressures. That posture should be reflected in further deceleration in the monetary aggregates in the years ahead and is an essential ingredient in any effective policy to restore price stability.

See Volcker (1981), p. 240. 


\section{HYPOTHETICAL ILLUSTRATION OF BASE DRIFT}

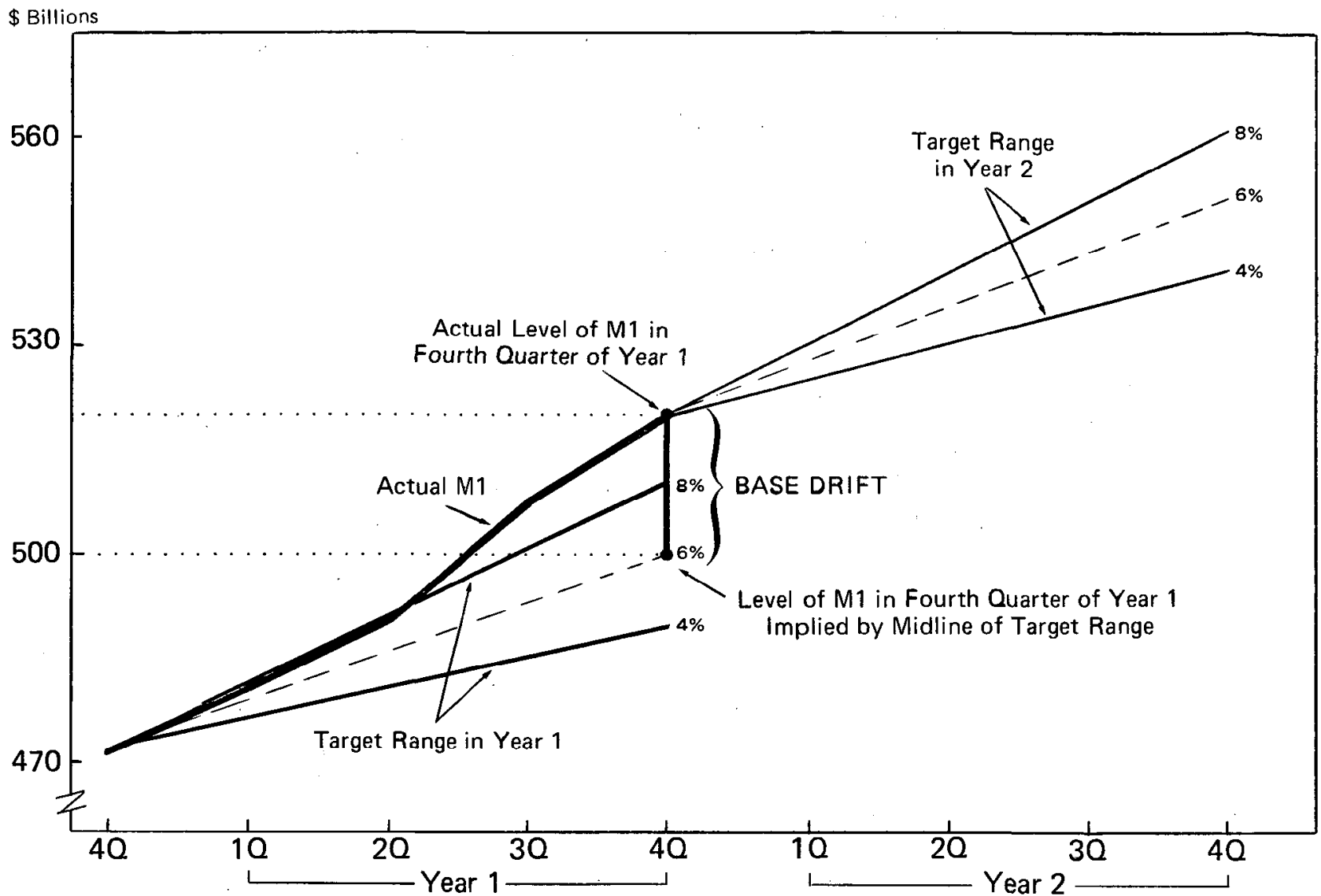

economists believe that the Fed should give greater emphasis to M1 than the other monetary aggregates, because M1 has had the most predictable relationship with nominal GNP over the longer run, and it is more amenable to Fed control than the other aggregates. Perhaps for these reasons, M1 is the monetary aggregate that receives the greatest attention from the general public. The trend growth rate of M1 was 6.7 percent over the nine-year period from the beginning of 1976, which was the first full year for which monetary targets were announced, until the end of the fourth quarter of 1984, compared to 5.6 percent in the preceding ten years. ${ }^{4.5}$ Further, there has been little change in the trend rate within the period. ${ }^{6}$

\footnotetext{
${ }^{4}$ These rates were calculated on a least squares basis. The calculation for the 1976-1984 period was made using the effective M1 data in Table I.

${ }^{5}$ Making similar comparisons for $M 2$ and $M 3$ would be more problematic than in the case of $\mathrm{Ml}$ because of the sharper break in the data when the definitions of the aggregates were changed at the beginning of 1980 .
}

In terms of the mechanics of the Fed's targeting procedure, one can allocate the discrepancy between the objective and actual M1 growth to two factors that at least in principle are separable: (1) insufficient reductions in the targeted rates of growth and (2) net upward base drift over the period. The next two sections of this article develop an estimate of the contribution of base drift to the discrepancy in the case of M1. Section II explains the construction of an "effective" M1 time series and a corresponding set of target ranges for effective M1 that are used in developing the estimate, and Section III reports the estimate. The remainder of the article is organized as follows. Section IV explains why base drift matters. Section $\mathrm{V}$ assesses the potential benefit of base drift in the case of permanent monetary distur-

\footnotetext{
${ }^{6}$ The 6.7 percent trend rate includes the period of exceptionally rapid growth in MI in 1982 and 1983, which in hindsight appears to have been appropriate in that as of early 1985, inflation has remained low. See the discussion in Sections $\mathrm{V}$ and VII of this article.
} 
bances. An alternative targeting procedure that would eliminate base drift is outlined in Section VI. The effective M1 data constructed in Section II provide evidence on the role of monetary targeting in the recent reduction of inflation. This evidence is discussed in a postscript in Section VII. Section VIII briefly summarizes the main points made in the article.

\section{II.}

\section{CONSTRUCTING A TIME SERIES FOR EFECTIVE M1 AND CORRESPONDING TARGET RANGES FOR EFECTIVE MI}

In order to measure base drift accurately over time, it is necessary to construct data series for both M1 itself and the M1 target ranges that are conceptually consistent both over time and with one another. Doing so is complicated by two events that occurred during the period. First, M1 was redefined at the beginning of 1980. Second, as explained below, the reported growth of M1 was distorted by the legalization and rapid growth of negotiable order, of withdrawal (NOW) accounts and other interest-bearing transactions accounts in several years during the period. This section describes. how each of these problems is handled. The mechanics involved are somewhat tedious but are essential to a full understanding of the results presented below.

Tables I and II contain the constructed data. Table I shows "effective" M1, i.e., M1 adjusted for the shifting of funds between various categories of deposit accounts occasioned by deregulation. These adjustments were made on an ex post basis using the latest estimates of the actual shifting that occurred. The details of the adjustments are described below. Table II shows the target ranges for the growth of effective M1. In the majority of the years covered, these ranges are the same as the ranges announced by the Fed. In one year where the growth rate of effective M1 diverged from the growth rate of reported M1 due to deregulation, however, it is necessary to infer the target for the growth of effective M1 from the publicly announced targets for the growth of reported M1. The guiding principle is to develop a series for the target ranges that indicates the growth rate of effective M1 that the Fed sought for each

${ }^{7}$ It should be noted that the potential problems with base drift were recognized by several economists shortly after the Fed began announcing targets. See, in particular, Poole (1976) and Kane (1975). year, whether the rate was expressed or implied. The nature of each adjustment is described below. ${ }^{8}$

\section{Change in the Definition of M1}

M1 as it was defined before 1980, which is referred to as "old M1" in this article, included mainly "currency in the hands of the public and demand deposits at commercial banks. In 1980, a "new M1" series was defined that includes the major components of old M1 and, in addition, what are now designated "other checkable deposits" (OCD). OCDs include NOW accounts and automatic transfer service (ATS) accounts at commercial banks and thrift institutions, credit union share draft accounts, and demand deposits at mutual savings banks.'

Prior to 1980 the Fed established M1 targets in terms of old M1. Since 1980, the M1 targets have been set in terms of new M1. In measuring base drift it is necessary to calculate the deviation of the particular measure of M1 that was actually targeted in a given year from the midpoint of the target range for that year. Therefore, the most straightforward way to proceed is to calculate money growth and base drift prior to 1980 using old M1 and subsequently to make the calculation in terms of new M1. This is what was done. Fortunately, the difference between the respective dollar levels using the two definitions is small in the quarter when the definition was changed. ${ }^{10} \quad$ Specifically, new M1 exceeded old M1

\footnotetext{
${ }^{8}$ It is important to note that while the adjustments made in constructing the effective MI series (Table I) were made on an ex post basis, the adjustments to the target, ranges (Table II) were made on an ex ante basis. That is, estimates of the actual shifting of funds caused by deregulation were used in constructing the effective M1 series. In contrast, the adjustments to the target ranges. where they occur, reflect the deposit shifts that the Fed anticipated would occur during a year as seen at the beginning of the year.

${ }^{9}$ See footnote 1 in this article for the precise current definition of $M 1$, which, in addition to the changes made in 1980, incorporates some additional minor changes made in 1981. It should be noted that the Fed published data for two Ml series, known as $M-1 A$ and $M-1 B$, in 1980 and 1981. The M-1A measure, which was close to the pre-1980 M1, was dropped at the beginning of 1982, and $\mathrm{M}-1 \mathrm{~B}$ was designated as. M1. All references in this article to M 1 in 1980 and 1981 are to what was then designated M-1B.

${ }^{10}$ This small difference in dollar levels results from the netting out of two discrepancies. As noted above, M 1 as currently defined includes OCDS, while old MI excludes them, which tends to raise the level of M1 as currently defined relative to the level under the old definition. In addition however, old M1 included demand deposits of foreign commercial banks and foreign official institutions, which are excluded under the current definition. This second discrepancy raises the level of old $\mathrm{M} 1$ relative to the level under the current definition.
} 
Table I

\section{EFECTIVE M1}

(Quarterly Average Data)

(\$ billions)

\begin{tabular}{rc|rc} 
Quarter & M1 & $\frac{\text { Quarter }}{1}$ & \multicolumn{1}{c}{ M1 } \\
\cline { 2 - 4 } $1975: 4$ & 295.1 & $1980: 1$ & 394.3 \\
$1976: 1$ & 298.5 & 2 & 390.0 \\
2 & 303.3 & 3 & 404.5 \\
3 & 306.4 & 4 & 414.1 \\
4 & 312.1 & $1981: 1$ & 413.2 \\
$1977: 1$ & 317.9 & 2 & 417.9 \\
2 & 323.8 & 3 & 420.5 \\
3 & 330.8 & 4 & 424.1 \\
4 & 336.9 & $1982: 1$ & 435.4 \\
$1978: 1$ & 342.5 & 2 & 437.9 \\
2 & 350.4 & 3 & 444.8 \\
3 & 357.3 & 4 & 462.3 \\
4 & 361.1 & $1983: 1$ & 477.5 \\
$1979: 1$ & 364.4 & 2 & 491.8 \\
2 & 371.8 & 3 & 503.8 \\
3 & 380.8 & 4 & 510.0 \\
4 & $385.6 / 387.4$ & $1984: 1$ & 519.4 \\
& & 2 & 527.6 \\
& & 3 & 533.7 \\
& & 4 & 536.3
\end{tabular}

Notes for Table I

1. Data for $4 Q 75$ through $4 Q 79$ are based on the old definition of M1 to maintain comparability with the target ranges. These data were derived from the final data released by the Board of Govemors using the old definition. (The data through 1978 are contained in "Historical Money Stock Revisions," February 1979. The data for 1979 are contained in the Board's H.6 release dated January 10, 1980.) Subsequent data are based on the new definition, which was referred to as M-1B in 1980 and 1981. These data were derived from published data as of January 1985. For 4Q79, the first figure is for the old definition and the second figure is for the new definition. The difference between the two figures is $\$ 0.9$ billion.

2. Data for 1Q79-4Q79 are adjusted to correct for the shift of funds from demand deposits to ATS accounts following the authorization of ATS accounts in late 1978. ATS accounts were not included in M1 under the old definition, and the adjustment in 1979 added these funds back into M1. This adjustment raised the growth rate of $M 1$ from $4 Q 78$ to $4 Q 79$ by 1.25 percentage points. This adjustment and all adjustments in subsequent notes to this table are based on estimates published by the Board of Govemors.

3. Data for the second half of 1980 are adjusted to correct for shifts of funds from assets not included in the new definition of M1 into ATS accounts in anticipation of the legalization of NOW accounts nationwide scheduled for December 31, 1980. This adjustment reduced the growth rate of M1 from $4 Q 79$ to $4 \mathrm{QBO}$ by 0.5 percentage point. by less than $\$ 2$ billion or by roughly 0.5 percent on an effective basis as described directly below in the fourth quarter of 1979, just prior to the change in definition. For this reason, simply switching from the old M1 measure to the new measure in the first quarter of 1980 introduces only a small error in the cumulative base drift calculation.

\section{Adjustments for Shifts into and out of NOW Accounts and Similar Accounts Due to Deregulation ${ }^{11}$}

As pointed out above, the reported growth of M1 was distorted by the ongoing deregulation of transactions accounts on several occasions during the period covered by this analysis. Both the distortions themselves and the manner in which the Fed dealt with them differed from one year to the next. The following paragraphs describe the situation on each occasion and indicate the nature of the adjustments made in each case in constructing the data in Tables I and II.

1979. In late 1978 all commercial banks were permitted to offer ATS accounts, which are interestbearing transactions accounts functionally equivalent to NOW accounts. Funds switched from demand deposits to ATS accounts presumably retained the characteristics of transactions accounts. Therefore, shifts from demand deposits, which were in old M1, to ATS accounts, which were not, caused the reported growth of old M1 to understate the effective growth of M1 in 1979. Consequently, an estimate of the volume of funds shifted from demand deposits to ATS accounts was added to old M1 in 1979 in constructing the effective M1 series in Table I. This adjustment raised the M1 growth rate in 1979 by $1 \frac{1 / 4}{4}$ percentage points.

At the beginning of 1979 , the Fed announced a target range for reported M1 of $1 \frac{1 / 2}{2}$ to $4 \frac{1}{2}$ percent.

\footnotetext{
${ }^{11}$ All of the adjustments described in this article are based on estimates published by the Board of Governors of the Federal Reserve System.
}

\footnotetext{
4. Data for 1981 are adjusted to correct for the shift of funds from assets not included in the new definition of M1 into NOW accounts as a result of the legalization of NOW accounts nationwide. This adjustment reduced the growth rate of $M 1$ from $4 Q B 0$ to $4 Q B 1$ by 2.7 percentage points.

5. Shifts of funds associated with the legalization of NOW accounts nationwide are believed to have been substantially completed by the end of 1981 . In order to maintain a continuous series, however, the cumulative downward adjustment of $\$ 13.4$ billion applied to the $4 Q B 1$ figure was applied to all subsequent figures.
} 
At the time, the Fed estimated that shifts of funds from demand deposits to ATS accounts would reduce old M1 growth by 3 percentage points over the year. The $1 \frac{1}{2}$ to $4 \frac{1}{2}$ percent target range explicitly allowed for this anticipated reduction in the reported growth rate. ${ }^{12}$ The implication is that the Fed was willing to accept effective M1 growth in a range of $4 \frac{1}{2}$ to $7 \frac{1}{2}$ percent as shown in Table II.

1980. The Monetary Control Act of 1980, which was signed into law in March of that year, authorized NOW accounts nationwide effective December 31, 1980. Consequently, many banks in states where NOW accounts were not yet permitted marketed ATS accounts aggressively in the second half of 1980 to position themselves competitively for the anticipated legalization of NOWs the following year. In 1980, however, in contrast to 1979, the Fed set targets in terms of new M1, which included ATS accounts. For this reason, a different kind of adjustment for shifts into ATS accounts, was needed in constructing the effective M1 series for 1980, Specifically, since ATS accounts are included in new M1, the shifting of funds from demand deposits to ATS accounts did not affect new M1 and therefore required no adjustment. Some funds, however, were shifted into ATS accounts from savings accounts and other instruments not included in new M1. These shifts increased reported new M1. It was assumed that these latter funds largely retained their nontransactions character after they were shifted into ATS accounts and hence into new M1. This implies that reported new M1 growth overstated the effective growth of transactions balances in 1980. Therefore, an estimate of the portion of the growth of ATS and similar accounts due to transfers of funds from savings and other non-M1 instruments was subtracted from reported new M1 in the second half of 1980 in constructing effective M1 in Table I. This adjustment reduced the growth rate one-half of a percentage point in 1980.

In announcing its targets for 1980, the Fed recognized, that if NOW accounts were legalized during

\footnotetext{
${ }^{12}$ See "Monetary Policy Report to Congress" (March 1979), p. 196. It should be noted that the target range for reported growth was raised from $1 \frac{1 / 2}{2} 4 \frac{1}{2}$ to $3-6$ percent in the middle of 1979. (See "Monetary Policy Report to Congress" (March 1980), p. 187.) This increase reflected new estimates which indicated that the growth of ATS accounts would reduce the reported growth rate by only $1 \frac{1}{2}$ percentage points, over the year rather than by the 3 percentage points estimated at the beginning of the year. However, the implied target for effective growth was not changed, i.e., both the estimated impact of the shifting of funds and the target range for reported growth were revised by the same amount.
}

Table II

\section{EXPRESSED OR IMPUED ANNUAL TARGET RANGES FOR EFECTIVE MI AND CORRESPONDING ACTUAL EFECTIVE M1 GROWTH, 1975-1985}

\begin{tabular}{|c|c|c|c|}
\hline Target Period & Target Range & $\begin{array}{c}\text { Midpoint of } \\
\text { Target Range } \\
\end{array}$ & Actual \\
\hline $4 Q 75-4 Q 76$ & $4.5-7.5$ & 6.0 & 5.8 \\
\hline $4 Q 76-4 Q 77$ & $4.5-6.5$ & 5.5 & 7.9 \\
\hline 4Q77 - 4Q78 & $4.0-6.5$ & 5.25 & 7.2 \\
\hline $4 Q 78-4 Q 79$ & $4.5-7.5$ & 6.0 & 6.8 \\
\hline 4Q79-4Q80 & $4.0-6.5$ & 5.25 & 6.9 \\
\hline $4 Q 80-4 Q 81$ & $3.5-6.0$ & 4.75 . & 2.4 \\
\hline 4Q81 - 4Q82 & $2.5-5.5$ & 4.0 & 9.0 \\
\hline $4 Q 82-4 Q 83$ & $4.0-8.0$ & 6.0 & 10.3 \\
\hline 2Q83 - 4Q83 & $5.0-9.0$ & 7.0 & 7.4 \\
\hline $4 Q 83-4 Q 84$ & $4.0-8.0$ & 6.0 & 5.2 \\
\hline 4Q84 - 4Q85 & $4.0-7.0^{p}$ & 5.5 & - \\
\hline
\end{tabular}

1. The ranges in this table are the same as, or were derived from, the target ranges that were announced by the Federal Resenve at the beginning of the year to which the target applied. For 1979 and subsequent target years announcements have been contained in the Federal Reserve's annual Monetary Policy Report to Congress, which is usually published in the March issue of the Federal Reserve Bulletin. For 1976, 1977, and 1978, the announcements are contained in Bums (1976), Bums (1977), and Miller (1978), respectively.

2. The target ranges for 1979 and 1981 are adjusted for anticipated shifts into or out of NOW accounts or similar, accounts as explained in the text. The ranges for the periods $4 Q 79$ $4 Q 80$ and $4 Q 80-4 Q 81$ are the ranges that were set for what war then referred to as $\mathrm{M}-18$.

preliminary

the year, the legalization would cause shifts of funds. Because it was not clear at the beginning of the year if legalization would occur or when, no allowance was made for it in setting the range. Therefore, the 4 to $6 \frac{1}{2}$ percent announced range was the target range for effective M1 growth. ${ }^{13}$

1981. NOW accounts were authorized nationwide at the beginning of 1981, and this change produced substantial shifts of funds from non-M1 instruments,. such as savings deposits, to NOW accounts during the year. Presuming again that these funds retained

\footnotetext{
${ }^{13}$ See "Monetary Policy Report to Congress" (March 1980), p. 178.
} 
their nontransactions character, it follows that the reported growth of M1 overstated effective growth. At the beginning of the year, the Fed estimated that the shifting of funds would reduce effective M1 growth relative to reported growth by 2.5 percentage points. The $3 \frac{1}{2}$ to 6 percent range announced at the beginning of 1981 and shown in Table II reflects these anticipated shifts. ${ }^{14}$

The effective M1 data for 1981 in Table I reflect the most recent estimate of the actual NOW account effect, which indicates that in fact the shifts reduced the growth rate for the year by 2.7 percentage points. It should be noted that the effective M1 levels reported in Table I for 1981 incorporate both the 1981 adjustments and the adjustment for the final quarter of 1980, since any adjustment must be carried permanently in a continuously adjusted series such as this one. The two adjustments together put effective M1 $\$ 13.4$ billion below reported M1 in the fourth quarter of 1981 .

1982, 1983 and 1984. In order to maintain a consistent series, all of the data in Table I for 1982, 1983 and 1984 incorporate the $\$ 13.4$ billion adjustment made in the final quarter of 1981. No further adjustments, however, are made in these years. This absence of further adjustments may seem curious in view of the authorization of money market deposit accounts (MMDAs) in late 1982 and Super NOW accounts in early 1983. Since the MMDA accounts were not included in M1, any transfers of funds from accounts included in M1 to the MMDAs would cause the reported M1 data to understate effective growth of M1 if it is assumed that the funds retained their transactions character after the shift. On the other hand, since the Super NOW accounts were included in M1, any transfers of funds from nontransactions accounts not included in M1 to the Super NOWs would cause the reported M1 data to overstate the effective growth of M1 to the extent that the funds retained their nontransactions character after the shift. As it turned out, the Fed's estimates of these two shifts are roughly equal and therefore offsetting. ${ }^{15}$ For this reason, no further adjustments are made.

\footnotetext{
${ }^{14}$ In 1981, in contrast to other years in which such shifting occurred, the Fed released and focused on "shiftadjusted" (i.e., what this article has called "effective") M1 data, and it also announced its target range in terms of effective growth.

${ }^{15}$ See "Monetary Policy Report to the Congress" (February 1984), p. 80.
}

III.

\section{THE ESTIMATE OF CUMULATIVE BASE DRIFT}

With the "effective" M1 data and the corresponding target ranges in hand, the computation of cumulative base drift is straightforward. The heavy solid line in Figure 2 plots the effective M1 series from Table I. The target ranges attached to this line are the adjusted fourth quarter-to-fourth quarter target ranges for effective M1 given in Table II. (To avoid cluttering the chart, the numerical ranges are shown along the horizontal axis.) As the chart shows, M1 finished the year near the midpoint of its range on two occasions : in 1976 and in the second half of 1983. It ended 1981 slightly below the lower bound of the range, and it ended 1984 in the lower half of the range. In every other year, it ended the year either in the upper third of the range (1979) or above it (1977, 1978, 1980, 1982, and the first half of 1983).

This tendency to exceed the range more frequently than not has led to substantial net upward base drift over the period as a whole. One way to estimate the cumulative drift is to compare the actual level of M1 at a point near the end of the period with the level that M1 would have attained if the Fed had (1) hit the midpoint of its target range at the end of every year and (2) set the same ranges for growth rates that it actually set. The midlines of the target ranges drawn with dashed lines in Figure 2 indicate the path M1 would have followed if the midpoints had been hit. On this path, effective M1 would have been $\$ 477.2$ billion in the fourth quarter of 1954 , compared with the actual level of $\$ 534.5$ billion net of the definitional discrepancy in 1980 . The $\$ 57.3$ billion difference between these levels is a measure of the net upward base drift that occurred under the Fed's targeting procedure from the fourth quarter of 1975 through the end of 1984. In other words, about 25 percent of the increase in effective M1 during this nine-year period can be attributed to base drift. ${ }^{16}$

The estimate given above is a rough approximation of cumulative base drift because the Fed might have set somewhat different targets from those actually set if it had hit the midpoint of the range each year. For this reason, the estimate is unavoidably hypothetical.

\footnotetext{
${ }^{16}$ It should be noted that while base drift is measured here as any deviation from the midpoint of the target range, the Fed itself has avoided setting the midpoint of its range as a point target. In some years, it has explicitly indicated that growth at a rate different from the rate implied by the midpoint would be acceptable. Nevertheless, since the base for each target range is a point, it seems reasonable to quantify base drift in terms of deviations from the midpoints of the ranges.
} 


\section{ACTUAL LEVELS AND TARGET RANGES FOR EFFECTIVE M1"}

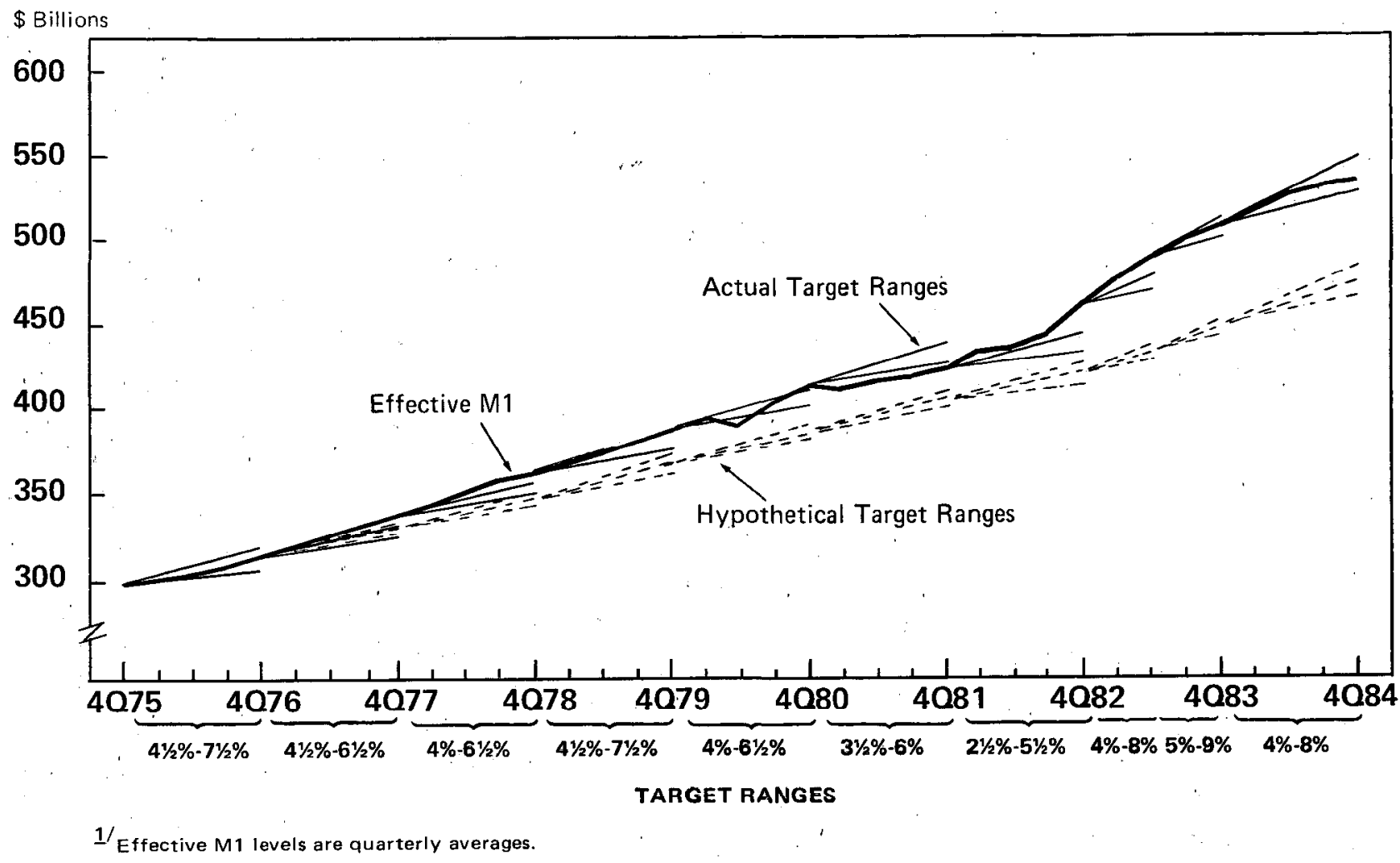

In particular, if changes in the midline target growth rates were negatively correlated with the base drift at the end of the preceding target year, the estimate would be biased upward. This is the case because with negative correlation, if there had been no base drift as in the hypothetical, situation shown by the dashed lines in Figure 2, the growth targets would have been higher on average than those that were actually set. Figure 3 shows the observed relationship between actual base drift and subsequent change in the target. There is no evidence of negative correlation. Indeed, Figure 3 suggests a positive correlation, which would imply that the above estimate is biased downward.

\section{IV.}

\section{WHY BASE DRIFT MATIERS}

The preceding section showed that cumulative base drift has been quantitatively significant during the years that the Fed has used the present targeting procedure. Moreover, because there has been both upward and downward base drift over the period, the cumulative measure understates the quantitative significance of base drift on a year-to-year basis. ${ }^{17} \mathrm{Be}$ yond its quantitative impact, however, allowing base drift would seem to rob the Fed's targeting strategy of some of its most important benefits.

\section{Erosion of Public Confidence in the Effectiveness of the Targeting Procedure}

The effectiveness of monetary targeting in controlling inflation depends largely on the public's confidence in the Fed's commitment to long-run control of the money stock. More specifically, the public must believe that the Fed will hit its announced targets on average over time. The contribution of the present targeting procedure to this confidence is almost certainly diminished by the frequent discrepancies between the targets and actual money growth in particular years and the incorporation of each miss in the base set for the next annual target.

\footnotetext{
${ }^{17}$ Annual base drift measured as a percentage of midline target levels at the end of each target year can be seen in Figure 3.
} 
Figure 3

\section{THE RELATIONSHIP BETWEEN BASE DRIFT AND SUBSEQUENT CHANGE IN MIDLINE TARGET GROWTH}

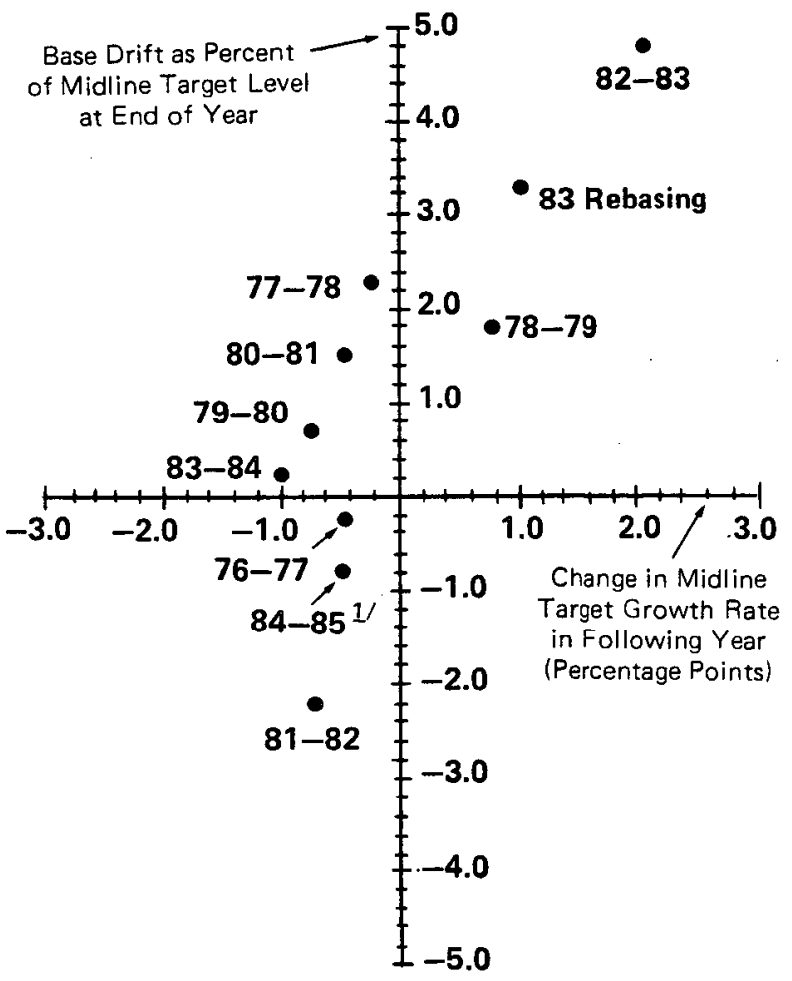

$1 /$ At the time this article was prepared, the Fed had not yet established a final target range for $M 1$ for 1985 . Therefore, this observation uses the 5.5 percent midline of the preliminary 4 to 7 percent range announced in July 1984, before the base drift was known.

\section{Diminished Incentive for the Fed to Hit Its Target}

A closely related point is that the allowance of base drift reduces the incentive for the Fed to hit its target in any particular year. At least as far as the procedure is concerned, any target miss that occurs in a given year is forgiven when the target for the next year is set, and the miss is therefore only temporarily in the public eye. ${ }^{18}$ The Fed's incentive to correct a deviation from the target that arises during a year is therefore reduced because no matter how large the

${ }^{18}$ In principle, base drift could be offset by moving subsequent targeted growth in the opposite direction. However, as seen in Figure 3, in practice change in targeted growth seems to be positively correlated with prior base drift. In any case, it would not seem desirable to use a targeting procedure where announced growth rates are routinely adjusted in response to prior money supply disturbances. The alternative procedure outlined in Section $\mathrm{VI}$ would not require such routine adjustment. deviation might be at the end of the year, the money stock is back on target when the new range is set. This feature of the present targeting procedure substantially reduces the disciplinary benefits of monetary targeting.

\section{Propagation of Transitory Disturbances}

The secular inflation rate tends to follow the trend rate of M1 growth over time. With unbiased monetary targeting, where target misses are truly random, the Fed could control inflation on average with the current targeting procedure as long as persistently noninflationary target paths were set. Even in these circumstances, however, allowing base drift would be an inferior targeting strategy.

Figure 4, which is similar to Figure 1, illustrates this point with another hypothetical example. In the first of the two years shown, actual M1 grows at a rate close to the midline of the target range through the first three quarters of the year. It then declines in the final quarter of the year to point $\mathrm{B}$, which is only slightly above the 4 percent lower bound of the range. The growth rate targeted in the second year is shown to be the same as in the first year. Because of the downward base drift, however, the level of the target path given by the midline of the range has declined by the difference between points $\mathrm{C}$ and $\mathrm{B}$. That is, the target path in the second year is $\$ 9$ billion below what it would have been if the base had not been allowed to drift. This hypothetical example has its counterparts in actual experience. As shown in Figure 2, above-target growth in 1978 significantly raised the level of the target path for 1979, and belowtarget growth in 1981 lowered the path for 1982.

To the extent that short-run target misses are due to transitory shifts in credit or money demand, ${ }^{19}$ base drift needlessly allows temporary disturbances to affect the money stock and the price level permanently. Consequently, uncertainty about the future price level tends to be greater with base drift than without it. The contribution that monetary targeting makes to economic efficiency by reducing uncertainty surrounding the future price level is therefore smaller when base drift is built into the targeting procedure. ${ }^{20}$ In short, because M1 growth is prone to significant quarterly disturbances that would otherwise be transitory, it would not appear to be desirable for the Fed's targeting procedure to build these disturbances into the following year's target path.

\footnotetext{
${ }^{19}$ See Goodfriend (1982).

${ }^{20}$ For more discussion of this point see Goodfriend (1984).
} 


\section{EFFECT OF A SHORT-RUN DISTURBANCE ON THE LONGER RUN TARGET}

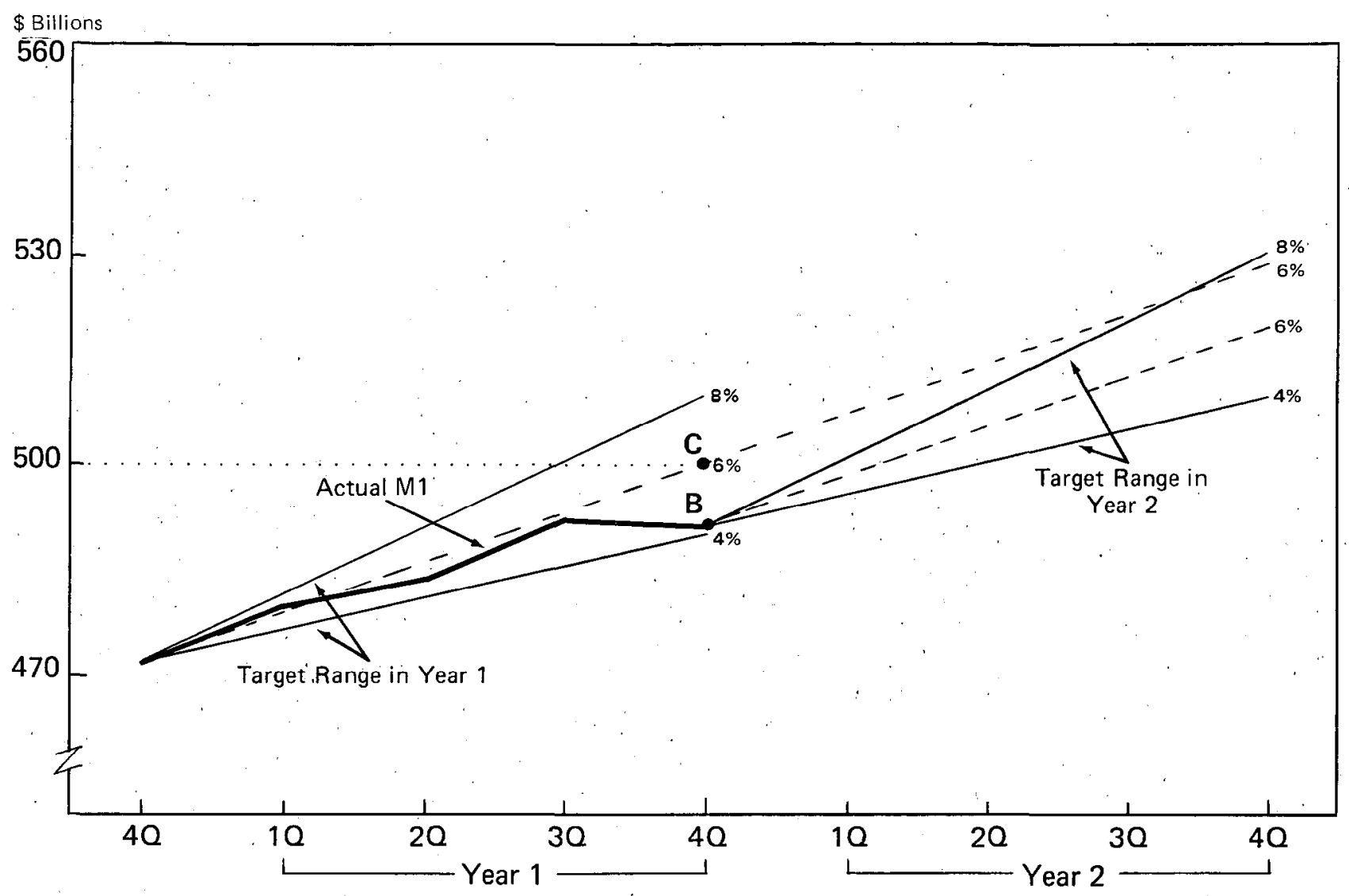

V.

\section{BASE DRIFT AND "PERMANENT" MONETARY DISTURBANCES}

Figure 2 shows that a sizable portion of the cumulative upward base drift to date arose at the end of the 1982 targeting year and during the 1983 targeting year. As is well known, the velocity of M1 declined unusually sharply in the late stages of the recession that ended in the fourth quarter of 1982 and expanded unusually slowly during the first year of the recovery. In this situation, the Fed deliberately allowed M1 growth to exceed its target range substantially in the second half of 1982 in order to prevent the economy from weakening further. ${ }^{21}$ Since it thought that the decline in velocity might be permanent, the Fed apparently felt comfortable basing its 1983 range at the high actual level of M1 in the fourth quarter of 1982. ${ }^{22}$

\footnotetext{
${ }^{21}$ See "Monetary Policy Report to Congress" (March 1983), p. 134.
}

On the basis of this episode, it might be argued that base drift is a desirable feature of the Fed's targeting strategy, since it allows the Fed to accommodate permanent disturbances in the relationship between income and the public's demand for money. Even if it were. possible to identify such permanent disturbances at the time they occur, however, it does not follow that allowing base drift as a routine feature of the targeting procedure would be either necessary or desirable. Faced with such a disturbance, it might be necessary for the Fed to raise its targeted growth rate temporarily or to raise, the level of the target path. Discretionary adjustments of the targets in reaction to conclusive evidence of permanent monetary disturbances, however, would be very different from rou-

\footnotetext{
${ }^{22}$ Similar reasoning led the Fed to set a new base for the period between the second quarter of 1983 and the fourth quarter of 1983 after M1 growth had exceeded its original 1983 range during the first half of the year. It should be noted that the Fed de-emphasized M1 between October 1982 and July 1984. The 1983 M 1 range was referred to officially as a "monitoring" range.
} 
tinely permitting any base drift to affect the target path.

\section{VI.}

\section{AN ALTERNATIVE TARGETING STRATEGY}

Two relatively simple changes in the Fed's targeting procedure would eliminate base drift and the problems associated with it. ${ }^{23}$ First, whatever money growth rate the Fed chooses to target in a given year, the base level for the target path should be the midpoint of the target range for the preceding year. In terms of Figure 1, the base level for the midline of the second year range should be the end point of the first year midline, or $\$ 500$ billion. This change would be sufficient to eliminate base drift. ${ }^{24}$ A second helpful modification, although strictly speaking not needed to eliminate base drift, would be to set the upper and lower bounds of the target range in terms of a band rather than the present wedge. The band would give the Fed the same room to maneuver throughout the targeting year. In particular, the Fed would have more room to maneuver early in a targeting year, when it might be desirable to deal gradually with money supply disturbances inherited from the previous targeting year.

Figure 5 shows how this procedure would work using the hypothetical data from Figure 4. As drawn, the chart indicates that the 6 percent target for money growth in the first year is retained in the second year. If the targeted growth rate were. lowered to, say, 5 percent in year 2 , the slope of the path would be lowered in the second year, but the base would still be the $\$ 500$ billion level given by the midline of the year 1 target range in the fourth quarter of the first year. The width of the band could be 2 or 3 percentage points of the targeted level. Obviously, a narrower band would encourage greater monetary control in the short run and vice versa.

In the example in Figure 5, actual M1 ends year 1 near the lower bound of the target band. The example can be used to illustrate the advantages of both of the modifications suggested above. Regarding the first modification, since point A would be the year 2 target, the modified procedure would require the Fed to aim to offset the first year shortfall in year 2 rather than forgiving the miss as under the present pro-

\footnotetext{
${ }^{23}$ These modifications were originally suggested by Poole (1976), pp. 255-57.

${ }^{24}$ If there were conclusive evidence of a permanent monetary disturbance, the base could be adjusted to take account of it, but such adjustments would only be made under exceptional circumstances.
}

cedure. The Fed would also have a stronger incentive to prevent a target miss from occurring in year 1 . This additional discipline would almost certainly increase the public's confidence in the Fed's ability to achieve its longer run objective of fostering steady, noninflationary growth in the money supply.

Regarding the second modification, it would be much easier for the Fed to use the year 1 target as the base for year 2 with a target band than with a wedge. As should be evident from Figure 5, if the Fed were to eliminate base drift but retain the wedgeshaped range from the old procedure, the money supply would be more likely to begin each new targeting year outside the range. This situation would be difficult for the Fed and confusing to the public. Using a band would allow the Fed to move the money supply gradually back to the target midline while remaining inside the target range.

\section{VII. \\ A POSTSCRIPT ON THE ROLE OF MONETARY TARGETING IN THE RECENT REDUCTION IN INFATION}

The United States has experienced a sharp reduction in inflation since 1980. For example, annual inflation as measured by the GNP deflator declined from 10.2 percent in 1980 to 4.3 percent in 1982 and has remained below 4 percent since then. The Fed must be given credit for pursuing the restrictive monetary policy that made this reduction in inflation possible. What role did monetary targeting per se play in achieving the reduction.? The effective M1 data in Table I provide some evidence on this question.

Inflation actually increased sharply during the first five years of monetary targeting. Annual inflation as measured by the GNP deflator rose from 4.7 percent in 1976 to 8.2 percent in 1979 and 10.2 percent in 1980. As shown in Table II, effective M1 overshot the upper bound of the Fed's target ranges in 1977 and 1978, and it came in within the upper third of the implied range in 1979. This performance created doubts about the Fed's commitment to its money supply targets and tended to encourage the increase in inflation in the late 1970s.

After renewing its commitment to disinflationary policy in October 1979, the Fed again let effective M1 overshoot its target in 1980, and the inflation rate remained high throughout that year. Then, in sharp contrast to the preceding four years, effective M1 actually undershot its range in 1981. As the data in Table I show, effective M1 grew 4.6 percentage 
Figure 5

\section{A TARGET BAND TO ELIMINATE BASE DRIFT}

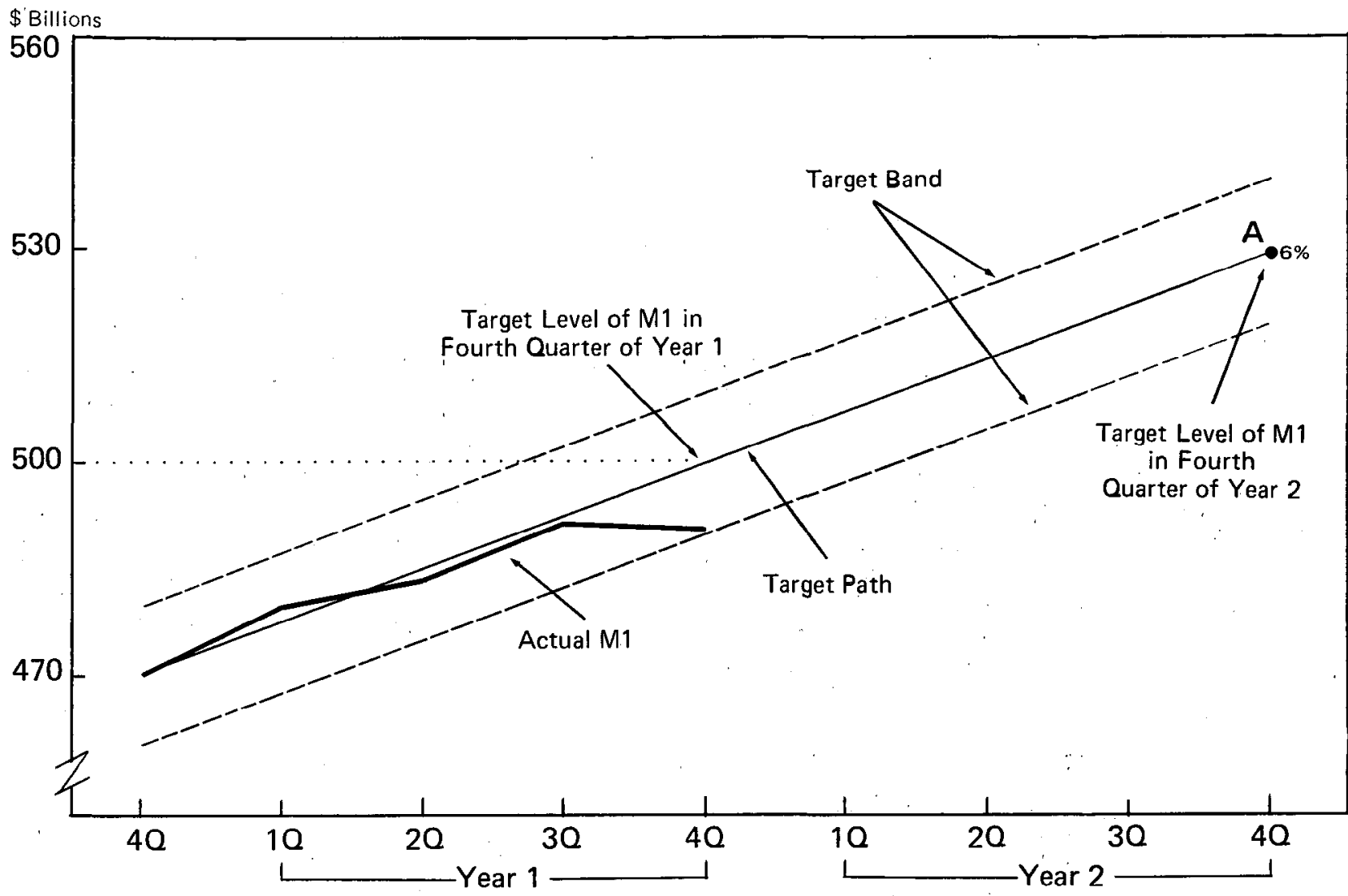

points slower in 1981 than its average annual growth over the preceding five years. ${ }^{25}$ Further, the 2 percent downward base drift in 1981 (see Figure 3) was built into the 1982 target path. This slower M1 growth was not the gradual deceleration built into the Fed's announced targets. Rather, it was a sharp deceleration that brought about an 'unexpectedly rapid decline in inflation-and may have worsened the 19811982 recession. ${ }^{26}$ In short, the discipline of mone-

${ }^{25}$ The effective M1 data in Table I may understate the deceleration somewhat, since, as noted in Section II, the data in the Table I series for the years prior to 1980 are based on the old definition, which excluded OCDs. Since OCDs began to grow significantly more rapidly in the late 1970s, an effective M1 series that uses the current definition throughout shows more rapid growth in the five years preceding 1981 and hence a sharper deceleration in 1981. Specifically, average annual effective growth in the five years preceding 1981 under the current definition is 7.4 percent, and the 1981 deceleration is therefore 5.0 percentage points.

${ }^{26}$ It should be noted that during the course of 1981 , the Fed felt that the weakness in M1 growth might be due in part to a lasting decrease in velocity resulting from improvement in cash management practices. Its limited reaction to the weakness in $\mathrm{M} 1$ was also affected by relatively strong growth in M2 and M3. See "Monetary Policy Report to the Congress" (March 1982), p. 129. tary targeting per se does not appear to have contributed significantly to the reduction in inflation. Instead, it appears that the reduction was due to the shock of an unanticipated undershooting, of the M1 target range following a four-year period during which growth either exceeded the range or came in well in the upper portion of the range.

By the summer of 1982, the unusual decline in M1 velocity together with the recession and developing strains in financial markets led the Fed to deemphasize its M1 target. M1 grew over the next four quarters at a very high 12.3 percent rate. In retrospect, the 1982 decision to accommodate the increased demand for M1 appears to have been appropriate in the sense that inflation has remained low.

An argument can be made, however, that the unusual decline in velocity in 1982 and some of the strain in financial markets that accompanied it have been due to the substantial deceleration in the growth of effective M1 in 1981 and the sharp reduction in actual inflation that followed. It was reasonable to expect that velocity would decline as falling 
inflation reduced nominal interest rates and lowered the cost of holding money. But it was extremely difficult to predict either how much or how quickly the public would revise its inflationary anticipations downward in the face of the pronounced monetary shock ; hence, it was particularly difficult to forecast the size and timing of the decline in velocity. As mentioned above, in retrospect rapid money growth in 1982-1983 has proven to be appropriate. Nevertheless, making monetary policy choices during a rapid disinflation is particularly difficult. If M1 had followed the gradual announced deceleration built into the targets, inflation would more likely have come down gradually, the recession and financial strains might have been less severe, and velocity might have fallen more gradually and predictably.

\section{VIII. \\ SUMMARY}

This article has described the nature of base drift. estimated its cumulative impact on the effective growth of M1 since 1975, and indicated several ways in which it undermines the Fed's present monetary targeting strategy. As noted in Section III, net base drift was substantially upward over the 1975-1984 period, although in retrospect some part of the drift that occurred in 1982 and 1983 may have been fortuitous in the sense that inflation has remained low through 1984. In any event, since there has been both upward and downward base drift during the period, the cumulative drift tends to understate the quantitative significance of base drift on a year-toyear basis. As pointed out in Section IV, the allowance of base drift greatly reduces the disciplinary features of monetary targeting and therefore probably reduces its effectiveness and credibility. The modifications of the present procedure noted in Section VI would eliminate base drift, give the Fed an incentive to control the growth of the money supply more closely in the short run, and in all likelihood increase the public's confidence in the Fed's commitment to restore and maintain price stability.

\section{References}

Axilrod, Stephen H. "U. S. Monetary Policy in Recent Years: An Overview." Federal Reserve Bulletin 71 (January 1985), pp. 14-24.

Burns, Arthur F. Statement before the Committee on Banking and Currency. U. S. House of Representatives, July 30, 1974, in Federal Reserve Policy and Inflation and High Interest Rates. Hearings before the Committee on Banking and Currency, House of Representatives, 93rd Congress, 2nd session, 1974, pp. 251-59.

Statement before the Committee on Banking, Currency, and Housing. U. S. House of Representatives, February 3, 1976, in Federal Reserve Bulletin 62 (February 1976), pp. 119-25.

Statement before the Committee on Banking, Finance, and Urban Affairs. U. S. House of Representatives, February 3, 1977, in Federal Reserve Bulletin 63 (February 1977), pp. 119-24.

Goodfriend, Marvin. "A Model of Money Stock Determination with Loan Demand and a Banking System Balance Sheet Constraint." Economic Review, Federal Reserve Bank of Richmond 68 (January/ February 1982), pp. 3-16.
"Rational Expectations, Interest Rate Smoothing, and the 'Optimality' of a Non-TrendStationary Money Supply Rule." Federal Reserve Bank of Richmond, February 1984.

Kane, Edward J. "New Congressional Restraints and Federal Reserve Independence." Challenge, November-December 1975, pp. 43-44.

Miller, G. William. Statement before the Committee on Banking, Finance, and Urban Affairs. U. S. House of Representatives, March 9, 1978, in Federal Reserve Bulletin 64 (March 1978), pp. 185-89.

"Monetary Policy Report to the Congress." Reports submitted to the Congress pursuant to the Full Employment and Balanced Growth Act of 1978. Federal Reserve Bulletin, March issues since 1979.

Poole, William. "Interpreting the Fed's Monetary Targets." Brookings Papers on Economic Activity, No. 1, 1976; pp. 247-59.

Volcker, Paul A. Statement before the Committee on Banking, Housing, and Urban Affairs. U. S. Senate, February 25, 1981, in Federal Reserve Bulletin 67 (March 1981), pp. 237-41. 


\title{
A MONETARIST MONEY DEMAND: F U N C T I O N
}

\author{
Robert L. Hetzel
}

\section{Introduction}

In the first part of this article, inflation as a monetary phenomenon is discussed. The discussion is from the perspective of the modern formulation of the quantity theory. (See, in particular, Chapter 2 in Friedman and Schwartz, Monetary Trends in the United States and the United Kingdom [2]). In the second part of the article, empirical estimation of the relationship between money growth and inflation is discussed. The article that accompanies this one; "The Behavior of the M1 Demand Function in the Early 1980s" contains the results of estimating this relationship for the post-Korean War period in the United States.

\section{The Quantity Theory Framework}

The modern formulation of the quantity theory places the determination of the price level within the analytical framework of supply and demand. The price level, or more appropriately its inverse, is the goods price of money. The price level is determined "by the interaction of the supply and demand for money.

A discussion of the determination of the price level must begin with the distinction between real and nominal variables. Nominal variables are either measured directly in current dollars or in a way that depends upon the use of dollars as a measure of value: Examples of nominal variables are the number of dollars in circulation and the dollar expenditure of the public on final goods and services. Because market, rates of interest, at least in principle, vary directly in response to changes in the future price level anticipated by the public, they are also examples of nominal variables. Real variables, in contrast, are measured in ways that do not make use of current dollars as the unit of account. Examples of real variables are the exchange rate between two commodities and final physical output. The quantity of money expressed in terms of its purchasing power over goods and services is a real variable.
The public cares about the real quantity of money it holds, while the actions of the central bank determine the nominal quantity of money available for the public to hold. The price level translates the real quantity of' money demanded, by the, public into the corresponding nominal quantity demanded. The price level varies in order to equate this nominal quantity demanded to the given nominal quantity supplied.

The quantity equation serves as a useful summary of the supply and demand relationship that determines the price level. In expression (1), the nominal money stock, $\mathrm{M}$, equals the product of a factor $\mathrm{k}$ and nominal expenditure, where nominal expenditure is expressed as the product of the price level, $\mathrm{P}$; and real expenditure, Y. By definition, $\mathrm{k}$ is the fraction of nominal expenditure held as nominal money balances.

$$
\text { ( } 1 \text { ) } \mathrm{M}=\mathrm{k}[\mathrm{P} * \mathrm{Y}]
$$

The definitional relationship shown in (1) can be transformed into a substantive economic hypothesis by interpreting it within the framework of a supply and demand relationship.

$$
\text { (2) } M=P[\mathrm{k} \cdot \mathrm{Y}]
$$

For this purpose, (1) is rewritten as (2). Now, M is interpreted as the nominal quantity of, money supplied. The product in brackets, $\mathrm{k} * \mathrm{Y}$, is interpreted as the real quantity of money demanded. Finally, the price level, P, adjusts to equate money demanded to money supplied. Below, expression (2) is given substance as a theory of the determination of the price level through specific hypotheses about the behavior of its components and their interaction. Interpretation of (2) within the framework of supply and demand, however, already entails the substantive economic hypothesis that the determinants of the supply of money can generally be considered as con ceptually distinct from the determinants of the demand for money. 


\section{The Money Supply}

From the perspective of the quantity theory, the nominal quantity of money is assumed to be determined largely independently of the public's demand for money. The public adjusts to the nominal money stock by varying the rate of its nominal expenditure. Conversely, the nominal money stock does not adjust to the rate of expenditure of the public: Each individual economic entity can proportion its money holdings to its expenditure by varying its money holdings, but collectively this behavior is not possible. Collectively, the public proportions its money holdings to its expenditures through a change in expenditures. From the quantity theory perspective, major changes in the nominal expenditure of the public reflect the public's adjustment to changes in the money stock.

\section{Money Demand}

Holders of money care about the real quantity of money they hold, that is, what they can purchase in terms of goods and services with their money holdings. The real quantity of money demanded is expressed in (2) by the terms $\mathrm{k} * \mathrm{Y}$. $\mathrm{Y}$ is considered here to be real annual expenditure on final output. The demand for real money holdings is, then, expressed as a fraction $\mathrm{k}$ of the annual real expenditure of the public. The term $\mathrm{k} * \mathrm{Y}$ expresses the fraction of a year's real expenditures that the desired real money stock would finance. The inverse of $\mathrm{k}$ is the expenditure velocity of money, that is, the number of times that a dollar on average is used in a year to effect transactions involving the sale of final goods and services. The term $\mathrm{k}$ is considered to be a predictable function of a small number of variables, for example, the nominal rate of interest and real income or wealth.

The statement that inflation is a monetary phenomenon is true in a trivial sense in that the price level is determined by the interaction of the demand for and the supply of money. This statement, however, refers to the empirical generalization that changes in the demand for money proceed in a fairly predictable, moderate fashion, while changes in the supply of money frequently occur that are large relative to changes in the demand for money.

\section{Adjustment of the Price Level to Money}

The price level is the rate of exchange between real output and dollars. It translates the real quantity of money desired by the public into a corresponding desired nominal quantity. As discussed below, the quantity theory assumes that ultimately the price level adjusts when, at the pre-existing price level, changes in the nominal quantity of money supplied produce excess supply or demand for money.

Changes in nominal money are not offset, except over short periods, by changes in $\mathrm{k}$, the factor expressing the way in which the public's demand for real money balances depends upon variables such as real income and the market rate of interest. On the contrary, changes in $\mathrm{k}$ may reinforce the effect of prior changes in money growth. For example, an increase in the rate of growth of the money supply will at some point result in a higher anticipated inflation rate, which will increase market rates of interest. As money becomes more expensive to hold, the public will reduce its real money holdings. This reduction, a reduction in $\mathrm{k}$, will drive the price level up beyond what was implied by the increased money growth.

Historically, changes in money growth have affected real expenditure before affecting the inflation rate. The effect of money on real expenditure and output is referred to as the nonneutrality of money and is not well understood theoretically. According to the quantity theory tradition, however, this effect causes movements in the money supply to be the major source of the business cycle. As explained below, the quantity theory assumes that the ultimate impact of changes in money is on changes in the price level, not on real economic activity.

Nothing about the number of dollars in circulation affects in any fundamental way the real resource endowments of an economy, the technological capacity of an economy to transform endowments into output, or the preferences of individuals with respect to consumption of this output. For these reasons, a change in the nominal quantity of money cannot exert a permanent effect on real economic activity.

The hypotheses of this section can be summarized by reference to expression (2). A change in $M$ will not be absorbed by an offsetting change in $\mathrm{k}$, nor will a change in $\mathrm{M}$ affect $\mathrm{Y}$ in a lasting way. A change in $M$ must ultimately affect P. The sections that follow constitute a discussion of one way of quantifying the 
empirical relationship existing between money and price level.

\section{Empirical Association of Money Growth and Inflation}

A functional form is suggested in this section for examining the empirical evidence on the ability of the, growth rate of the money supply to predict inflation. (See Hetzel [3].) The following section displays the associated algebra.

Initially, a functional form is posited to explain the public's demand for real money holdings. This form is assumed to depend upon time, a nominal interest rate, and real expenditure. In order to estimate this functional form, dependent and independent variables must be chosen and a lag structure imposed on the latter. This task is effected through choice of an "adjustment equation" in the spirit of (2) in which the public adjusts its real money holdings through variation in the price level. The price level varies so as to translate the real money holdings desired by the public into a desired nominal quantity equal to the nominal quantity supplied by the central bank. Combining the basic functional form expressing the public's demand for real money holdings with this adjustment equation yields an expression relating the price level to contemporaneous and lagged values' of the nominal interest rate, real expenditure, and the nominal money stock. This expression can be estimated as a regression equation.

\section{Algebra}

A standard money demand function is as follows:

$$
m_{t}^{*}=f\left(X_{t}\right)=e^{k} e^{-a t} R_{t}^{-b} Y_{t}^{c}
$$

Real money holdings, the ratio of nominal money holdings to the price level, $\mathrm{M} / \mathrm{P}$, are denoted by $\mathrm{m}$. Real money holdings demanded by the public; $\mathrm{m}^{*}$, depend upon time $(\mathrm{t})$, a nominal interest rate $(\mathrm{R})$, and real expenditure ( $\mathrm{Y})$. Also, $\mathrm{k}$ is a constant; a is the trend rate of growth in the demand for money; and $b$ and $c$ are the elasticity of the demand for real money balances with respect to the nominal rate of interest and real expenditure, respectively. The symbol e denotes the base of the system of natural logarithms.

An adjustment equation in the quantity theory spirit is (4), where $\ln$ is the natural logarithm. (A difference in the logarithms of variables, multiplied by 100 , can be interpreted as the percentage difference in the variables.)

\section{(4) $\ln \mathrm{P}_{t}-\ln \mathrm{P}_{\mathrm{t}-\mathrm{i}}=\lambda\left[\ln \mathrm{M}_{\mathrm{t}}-\ln \mathrm{m}_{\mathrm{t}}{ }^{*} \mathrm{P}_{\mathrm{t}-1}\right]$.}

The percentage change in the price level is assumed to be a constant fraction $\lambda$ of the percentage discrepancy between the nominal money stock determined by the central bank and the nominal money stock desired by the public at the inherited price level. (The desired nominal money stock is the product of the desired real money stock and the price level.) Combining (3) and (4) yields

$$
\begin{gathered}
\ln \mathrm{P}_{\mathrm{t}}=-\frac{\lambda}{1-(1-\lambda) \mathrm{L}} \ln \mathrm{f}\left(\mathrm{X}_{\mathrm{t}}\right)+ \\
\frac{\lambda}{1-(1-\lambda) \mathrm{L}} \ln \mathrm{M}_{\mathrm{t}}
\end{gathered}
$$

$\mathrm{I}$, is a shift operator, $\mathrm{L}^{\mathrm{k}} \mathrm{X}_{\mathrm{t}}=\mathrm{X}_{\mathrm{t}-\mathrm{k}}$, that is, it shifts the date of a variable into the past. Also,

$$
\begin{aligned}
\frac{\lambda}{1-(1-\lambda) \mathrm{L}}= & {[1+(1-\lambda) \mathrm{L}+} \\
& \left.(1-\lambda)^{2} \mathrm{~L}^{2}+\ldots\right]
\end{aligned}
$$

The immediately preceding term indicates that the variables it multiplies, $\ln f\left(X_{t}\right)$ and $\ln M_{t}$ in (5), enter as a sum of contemporaneous and past values with weights that decline geometrically, that is, by some power of $(1-\lambda)$. In (6) below, $\ln M_{t}$ and the variables that comprise $\ln f\left(X_{t}\right)$ are allowed to enter with a simple distributed lag pattern, rather than with a geometrically declining lag pattern, that is, the coefficients on the affected variables are not constrained to follow a particular pattern. (The geometrically declining lag pattern was assumed only for expositional purposes.)

Below, in (6) $\ln f\left(X_{t}\right)$ is written out as follows :

$$
\ln f\left(X_{t}\right)=k-a t-b \ln R_{t}+c \ln Y_{t}
$$

(The use of first differences, indicated by the A, causes the $\mathrm{k}$ and the $\mathrm{t}$ in the at term to drop out.)

\section{Estimation}

The functional form (5) is shown below in first difference form as regression equation 
(6)

$$
\begin{aligned}
& \Delta \ln \mathrm{P}=\mathrm{a}+\sum_{\mathrm{i}=0}^{-\mathrm{n} 1} \mathrm{~b}_{\mathrm{i}} \Delta \ln \mathrm{R}_{\mathrm{i}}- \\
& \underset{\mathrm{i}=0}{\mathrm{~N}^{\mathrm{n} 2}} \mathrm{c}_{\mathrm{i}} \Delta \ln (\mathrm{Y} / \mathrm{N})_{\mathrm{i}}+ \\
& \underset{\mathrm{i}=0}{\mathrm{n} 3} \mathrm{~d}_{\mathrm{i}} \Delta \ln (\mathrm{M} / \mathrm{N})_{\mathrm{i}}+\mathrm{u} \text {. }
\end{aligned}
$$

The 8 notation indicates the use of simple distributed lags. The trend rate of growth of the demand for money is a, while the respective sums of the $b_{i}$ and $c_{i}$ coefficients are the. elasticity, of the demand for real money balances with respect to the nominal rate of interest and real income, respectively. The error term is $\mathrm{u} . \mathrm{N}$ is population. Dividing real expenditures and nominal money by population means that a change in population that leaves per capita real expenditure and per capita nominal money holdings unchanged will not affect the price level.

Regression equation (6) is in principle amenable to estimation as a money demand function. The price level, rather than the real money holdings of the public, is the dependent variable. The derivation of (6), however, was performed under the quantity theory assumption that nominal money holdings are given to the public. The behavior of the price level, therefore, determines the behavior of real money holdings.

The estimation of (6) as a money demand function presents a number of difficulties. The specification of the adjustment equation (4) should in principle determine the specification of the functional forms (5) and (6). The theory needed to specify (4) in a satisfactory way is, however, largely lacking. What is needed is a theory explaining the way in which a change in nominal money produces changes over time in the price level. The way in which a change in nominal money breaks down in the short run into changes in real expenditure and in the price level is, however, one of the major unresolved issues in economics. Satisfactory estimation of money demand functions requires a better understanding of the dynamics of the process whereby the public eliminates discrepancies between actual and desired real money holdings.

Failure to account satisfactorily for these dynamics could cause the behavior of the central bank to affect the apparent structural stability of the estimated money demand regression. Estimation of (6) could be affected by supply side, rather than solely demand side, behavior. For example, if the central bank were to cause the behavior of nominal money to become more predictable, some theories would predict a reduction in the time required for a change in money to change the price level. The mean lag associated with the estimated distributed lag coefficients on money in (6) would fall.

The above comments need to be qualified, however, by noting that estimation of (6) can still offer evidence on shifts in the public's money demand function. Over a period of time long enough for the price level to adjust fully, the quantity theory implies that real money holdings are demand determined by the public. A persistent underprediction of the price level, say, with (6), and thus overprediction of the level of real money holdings, must be explained by the behavior of the demand for money, not the supply of money. This hypothetical underprediction of the price level would reflect a leftward shift in the public's money demand function.

A problem related to those discussed above is that over periods of time short enough for money to affect real economic activity, the price level, the dependent variable in (6), and the rate of interest and the rate of real expenditure, independent variables in (6), are simultaneously determined. A single equation estimation procedure applied to (6) will not capture this mutual interaction and, consequently, will yield biased estimates of the true parameters of the public's money demand function.

Finally, the true functional form of the money demand function might not be (3), but might be an alternative functional form such as the Cagan [1] money demand function. With this latter form, real money holdings depend upon the inflation rate expected by the public. The price level, consequently, depends upon the money supply expected to obtain in the future. Estimation of the parameters of the money demand function requires knowledge of the process generating the money supply. (See Sargent [4].) Ordinarily, estimation of (6) would be expected to produce a sum of coefficients on the contemporaneous and lagged money terms close to one so that a one percentage point change in money growth would lead to a one percentage point change in the inflation rate. If the Cagan money demand function were the appropriate function, however, the sum of estimated coefficients on money might differ from one in that the money terms are serving as a proxy for expected money growth.

Despite, the problems discussed above, estimation of (6) remains a useful way of organizing an overview of the data relevant for assessing the stability of 
the public's money demand function. Problems of specification and simultaneous equations bias do not alter the fact that (6) depends upon the public's money demand function in an essential way. Stability over time of an estimated regression equation like (6) constitutes empirical evidence in favor of a stable money demand function. Estimation of (6) permits, in particular, an assessment of the degree to which the empirically regular association between money growth and inflation, predicted by the quantity theory, exists. This estimation is performed in the following article within a context of a discussion of whether the recent deregulation of the financial systern has altered the character of M1.

\section{References}

1. Cagan, Phillip. "The Monetary Dynamics of Hyperinflation," in Milton Friedman, ed., Studies in the Quantity Theory of Money. Chicago: The University of Chicago Press, 1956.

2. Friedman, Milton, and Anna J. Schwartz. Monetary Trends in the United States and the United Kingdom: Their Relation to Income, Prices, and Interest Rates, 1867-1975. Chicago: The University of Chicago Press, 1982.

3. Hetzel, Robert L. "Estimating Money Demand Functions." Journal of Money, Credit, and Banking 16 (May 1984), 185-193.

4. Sargent, Thomas J. "The Demand for Money during Hyperinflations under Rational Expectations." International Economic Review 18 (February 1977), 


\title{
THE BEHAVIOR OF THE M1 DEMAND FUNCTION IN THE EARLY 1980s
}

\author{
Robert L. Hetzel
}

\section{Introduction}

Since the last half of 1982, the rate of inflation has been below the rate that would have been predicted on the basis of the historical relationship between the rate of growth of M1 and the rate of inflation. This fact indicates that a rightward shift in the public's M1 demand function has occurred. Two alternative explanations of the nature of this shift are exposited in the first part of this article. Both explanations assume that the shift is associated with the deregulation of the financial system in the early 1980s. One explanation assumes that there was a onetime permanent change in the character of the public's M1 demand function. The other assumes that shifts will occur in the public's M1 demand function while the public adjusts to the deregulation of the financial system; however, after this adjustment is completed, the M1 demand function will reassume its pre-1980s characteristics.

The breakdown of the prohibition of the payment of interest on the checkable deposits of consumers has been associated with the introduction of various kinds of interest-bearing transactions accounts, known as other checkable deposits (OCDs). The first explanation offered for the recent behavior of the public's M1 demand turns on the fact that M1 now includes instruments suitable for saving, as well as for effecting transactions. In the spirit of this first explanation, it is conjectured that the public's M1 demand function has come to resemble permanently its demand function for M2 as formerly defined, which included savings, as well as transactions, balances. (This explanation is suggested by Friedman and Schwartz (1983/1984) and is referred to below as the Friedman/Schwartz hypothesis.) The second explanation offered turns on the fact that the new interest-bearing checkable deposits require minimum balances. In the spirit of the second explanation, it is conjectured that consumers, in the process of establishing new OCD accounts, make onetime transfers of funds from savings accounts in order to satisfy these minimum balance requirements. (This explanation is suggested by Cook and Rowe (1984) and is referred to below as the initial balance hypothesis.)

Both of these hypotheses predict a rightward shift in the public's M1 demand function in the early 1980s. It is, therefore, not possible currently to use the behavior of the public's real M1 balances in order to discriminate between them. With the passage of time and the subsidence of new deregulation affecting transactions balances, their implications for the behavior of the public's real M1 balances diverge. This latter fact is exploited below in order to make two sets of predictions of inflation for 1985, given an assumption about the rate of growth of M1 and given the assumption that the rate at which new OCDs are being introduced falls to a low level sustainable in the long run. Given the validity of this latter assumption, these contrasting predictions of inflation should offer evidence during 1985 useful in discriminating between the two hypotheses discussed here and, therefore, useful in assessing the contemporaneous character of the public's M1 demand function.

\section{Two Alternative M1 Demand Functions}

Especially after the nationwide introduction of interest-bearing NOW accounts in January 1981, M1 has comprised deposits suitable for saving as well as for effecting transactions. In this respect, M1 is now similar to M2 as defined prior to January 1980. ${ }^{1}$ The choice of an M1 demand function that takes account of the current presence in M1 of interest-bearing

\footnotetext{
${ }^{1}$ In 1980, M1 was redefined to include the various new kinds of interest-bearing checkable deposits offered to consumers, NOW and ATS accounts and credit union share drafts. In January 1983, Super NOW accounts were authorized and added to the definition of M1. Also in 1980, the monetary aggregate M 2 was redefined. Before 1980, M2, in addition to currency and demand deposits, comprised savings and small time deposits of banks plus time certificates of deposits other than the large negotiable certificates of deposit of large banks. After 1980, small time and savings deposits at depository institutions other than banks, money market mutual fund shares, and overnight Eurodollar deposits and overnight repurchase agreements were added to the definition of M2.
} 
checkable deposits is motivated by a suggestion of Milton Friedman and Anna Schwartz (1983/1984). Friedman and Schwartz have contended that the construction of a money series with consistent economic properties is better achieved by splicing the recent M1 time series, which includes interest-bearing checkable deposits, with the historical time series for old M2, rather than with the historical time series for M1, which excludes interest-bearing deposits.

The relationship of a particular definition of money to macroeconomic variables like the expenditure of the public and the level of market rates of interest is summarized by a money demand function. The introduction into M1 of instruments suitable for saving can reasonably be conjectured to have altered the parameters that characterize the M1 demand function in a way that moves them toward the values of the parameters that characterize the old M2 demand function. In particular, it is plausible that the current demand function for M1 would exhibit, relative to its pre-1981 behavior, a lower trend rate of decline in the demand for M1 and higher interest rate and income elasticities of demand for M1. If this conjecture is correct, the characteristics of the public's current M1 demand function probably lie in between those of the pre-1981 M1 demand function and those of the former old M2 demand function. ${ }^{2}$ With the passage of time, economists will be able to estimate the characteristics of the current M1 demand function with data that start in January 1981. At present, not enough time has elapsed in order to make this estimation feasible. Consequently, in order to give the Friedman/Schwartz hypothesis content, the somewhat arbitrary decision is made that the introduction of interest-bearing checkable deposits into the definition of M1 has caused the public's current M1 demand function to become identical to its former old M2 demand function.

In the above spirit, the following simple empirical evaluation is performed in this article. A money demand regression equation is estimated that highlights the relationship between the rate of growth of the money supply and inflation. When this regression is estimated through the 1970s with M1 and

\footnotetext{
${ }^{2}$ Current M 1 does not include the time and savings deposits at commercial banks that were in old M2 (although it does include some deposits at thrift institutions that were not included in old M2). Also, the introduction of MMDAs decreases the attractiveness of OCDS as savings vehicles. On a priori grounds, it appears that old M2 served as a vehicle for saving to a greater extent than M1 does now. This line of reasoning suggests that the characteristics of the contemporaneous MI demand function lie in between the former M 1 and former old M2 demand functions.
}

simulated for the early 1980 s with M1, inflation is overpredicted. When this regression is estimated through the 1970s with old M2, however, and then simulated for the early 1980 s with M1, inflation is reasonably well predicted. These results provide empirical support for the Friedman/Schwartz hypothesis.

These same results, however, are also consistent with the initial balance hypothesis about the rightward shift in M1 demand. This hypothesis emphasizes the transfer of funds from savings accounts to meet minimum balance requirements assumed to accompany the opening of new OCD accounts. As long as the transitional period persists during which the public is opening new OCD accounts in response to deregulation, the public's demand for real M1 balances will be unusually strong. After this transitional period, however, the public's M1 demand should return to normal. The relationship that existed prior to the 1980 s between the rate of growth of M1 and the rate of inflation should again serve as a basis for predicting the rate of inflation.

Consequently, as pointed out in the introduction, after this transitional period, predictions of inflation will differ depending upon the validity of the Friedman/Schwartz or initial balance hypotheses. Again, these hypotheses are that the public's M1 demand function has come to resemble permanently its former old M2 demand function or, alternatively, that the public's M1 demand function will reassume its previous characteristics once consumers have had time to adjust to the removal of interest-rate ceilings. On the basis of these different hypotheses, two divergent sets of predictions for inflation are made for 1985 . The actual behavior of inflation in 1985 should, therefore, aid in discriminating between these hypotheses. Before these predictions are presented, the form of the money demand regression equations used to predict inflation is discussed. The ability of these regression equations to predict, recent inflation is also described.

\section{Estimating Money Demand Functions}

Money demand regression equations usually employ the ratio of nominal money to the price level as the dependent variable. Entering these two variables as a ratio, however, constrains the functional form very considerably. A less constraining functional form is employed here that makes the price level the dependent variable, while a distributed lag on present and past money becomes an independent variable, along with the real expenditure of the public and an 
interest rate. A similiar functional form was originally used by Harberger (1963) and more recently has been advanced by Laidler (1982, chap. 2), Fama (1982), and Coats (1982). A discussion of this form of money demand regression equation is presented in the preceding article in this Review, "A Monetarist Money Demand Function," and in Hetzel (1984).

The regression equation is shown below in firstdifferenced form. $\mathrm{P}$ is the price level; $\mathrm{R}$ the nominal rate of interest; $\mathrm{Y}$ real expenditure of the public; $\mathrm{M}$ nominal money; and $\mathrm{N}$ population. Also, $\mathrm{A}$ is the first difference operator; ln the natural logarithm; and $\mathrm{u}$ an error term. The trend rate of growth of the demand for money is a, while the respective sums of the $b_{i}$ and $c_{i}$ are the elasticity of the demand for real money balances with respect to the nominal rate of interest and real income, respectively. Regression equation (1) is estimated under the assumption that nominal money, $\mathrm{M}$, is given. The behavior of the price level, $\mathrm{P}$, therefore, determines the behavior of real money balances.

$$
\begin{aligned}
\Delta \ln P= & a+\underset{i=0}{-n 1} b_{i} \Delta \ln R_{i}- \\
& \underset{i=0}{-n 2} c_{i} \Delta \ln (Y / N)_{i}+ \\
& -n 32 \\
i=0 & d_{i} \Delta \ln (M / N)_{i}+u
\end{aligned}
$$

The estimation employs first differences of the natural logarithms of quarterly average observations, multiplied by 400 . Equation (1) then represents a regression of the annualized quarterly inflation rate on a constant and on contemporaneous and lagged annualized quarterly percentage changes in the nominal rate of interest, in real expenditure per capita, and in nominal money balances per capita. The interest rate is the 4-6 month commercial paper rate. Real expenditure is gross domestic purchases in 1972 dollars. ${ }^{3}$ Estimation is by ordinary least squares over

a Gross domestic purchases (GDP) equals gross national product (GNP) less exports plus imports. GDP is a better measure of expenditure by $U$. S. residents than GNP. Recently, the rise in the U. S. current account deficit has caused GDP to grow faster than GNP. The price level employed is the implicit GDP deflator. This index is more representative of the prices paid by U. S. residents than the GNP implicit price deflator because it excludes export prices and includes import prices. Recently, the GNP deflator has risen more rapidly than the GDP deflator because of the rise in the foreign-exchange value of the dollar and the fall in the price of imported oil. the interval from 1952Q1 to 1979 Q4. ${ }^{4}$ The estimation results using $\mathrm{M} 1$ are displayed in Table $\mathrm{I}$ in a form that shows the sum of the estimated distributedlag coefficients. ${ }^{5}$

The estimated constant term indicates a trend rate of decrease in the demand for M1 of about 2 percent per year. The sum of the estimated coefficients on the interest rate terms indicates a small, but statistically-significant, interest elasticity of the demand for M1. The sum of the estimated coefficients on the real expenditure terms indicates a real expenditure or income elasticity of the demand for M1 of about .5.

${ }^{4}$ The end date was chosen in order to employ an interval of estimation identical to the interval used in estimation with old M2. The old M2 series is available only through 1979Q4. The estimation employs M 1 as redefined in early 1980 to include other checkable deposits. Other checkable deposits grew from close to zero in 1975 to 4.3 percent of redefined M 1 in 1979Q4. (This percentage grew rapidly after the nationwide introduction of NOW accounts in 1981Q1. In 1981Q4, it was 17 percent.) By ending the estimation in 1979Q4, similar estimation results are produced using MI defined to include and exclude other checkable deposits.

${ }^{5}$ The regression employs simple distributed lags with lag lengths chosen in order to maximize the corrected $\mathrm{R}$ squared statistic. Examination of the autocorrelation and partial autocorrelation function of the residuals indicated that the errors are generated by a first-order autoregressive process. The estimation, therefore, was performed with a Cochrane-Orcutt procedure.

Table I

REGRESSION OF INFATION ON M1 GROWTH

\begin{tabular}{lcccc}
\hline$\Delta \ln P$ & constant & $\Delta \ln R$ & $\Delta \ln Y$ & $\Delta \ln M 1$ \\
& 2.19 & .045 & -.55 & .97 \\
$(.40)$ & $(.013)$ & $(.15)$ & $(.10)$ \\
\hline Range $=1952 Q 1$ to & $1979 Q 4$ & NOB $=111$ \\
NOV $=25$ & RSQ $=.48$ & SER $=1.44$ \\
$D-W=2.18$ & &
\end{tabular}

Notes: $M 1$ is $M 1$; $R$ the 4-6 month commercial paper rate; $Y$ gross domestic purchases in 1972 dollars; $P$ the implicit gross domestic purchases deflator. $M$ and $Y$ ore divided by the total population of the United States including armed forces overseas. $\Delta$ is a first difference operator; In the natural logarithm. NOB is the number of observations; NOV the number of variables estimated; RSQ the corrected R-squared; SER the standard error of the regression equation; $D-W$ the Durbin-Watson statistic. First-differenced variables are multiplied by 400 . Estimation uses simple distributed lags. The sum of the estimated coefficients is shown, with the standard error of the sum in parentheses.

R comprises 6 contemporaneous and lagged values; $Y, 7$ such values; and M1, 10 such values. Estimation performed with Cochrane-Orcutt procedure. First-order autoregressive parameter estimated as .41 with standard error of .08 . 
The negative coefficient on real expenditures indicates that a one percent increase in real expenditure or income would, for a given level of M1, produce a decline in the price level (an increase in real M1 balances) of about .5 percent. As indicated by the fact that the estimated coefficient on M1 is insignificantly different from one, a one percentage point change in the rate of growth of M1 produces a one percentage point change in the rate of inflation.

The results of estimating the money demand regression equation (1) with M2 as defined formerly (old M2) are displayed in Table II. The endpoint of the interval of estimation, 1952Q1 to 1979Q4, coincides with the discontinuance of publication of the old M2 series. The major differences in results from estimation with old M2, rather than with M1, are a smaller estimated trend rate of decline in money demand (a smaller constant term) and an increased income elasticity of money demand (a sum of coefficients larger in magnitude on the real expenditure terms). These differences result from the inclusion in old M2 of instruments used by consumers as saving vehicles, that is, small time and savings deposits at commercial banks.

Within-sample errors in predicting calendar year inflation rates are shown in Table III. The errors are generally smaller for predictions made with old M2 than with M1. With old M2, only two calendar year errors exceed 1.5 percentage points (1963, 1964), while with M1 five calendar year errors exceed 1.5 percentage points (1952, 1953, 1964, 1974, 1976) and two exceed two percentage points (1952, 1974). For M1, the root mean square of the calendar

Table II

REGRESSION OF INFATION ON OL M2 GROWTH

\begin{tabular}{lcccc}
\hline$\Delta \ln P$ & constant & $\Delta \ln R$ & $\Delta \ln Y$ & $\Delta \ln M 2$ \\
& .76 & $(.073$ & -.94 & .96 \\
& $(.46)$ & $(.013)$ & $(.16)$ & $(.087)$ \\
\hline Range $=1952 Q 1$ to $1979 Q 4$ & NOB $=111$ \\
NOV $=29$ & RSQ $=.58$ & SER $=1.31$ \\
$D-W=2.04$ & &
\end{tabular}

Notes: M2 is old M2, that is, as defined before, Jan. 1980. R comprises 6 contemporaneous and lagged values; $Y, 11$ such values; and M2, 10 such values. Estimation performed with Cochrane-Orcutt procedure. First-order autoregressive parameter estimated as .41 with standard error of .09. Othenwise, see first paragraph of notes to Table $I$. year errors from 1952 through 1979 is 1.1, while the mean absolute error is .87 . For M2, the root mean square of the calendar year errors from 1952 through 1979 is .89, while the mean absolute error is .74.

\section{The Recent Behavior of M1 Demand}

Regression equation (1), estimated with M1 as shown in Table I, was simulated with M1 over the out-of-sample period 1980Q1 through 1984Q3. The percentage error in predicting the price level is reported in the first column of Table IV. ${ }^{6}$ The pre-

${ }^{6}$ Because the regression is estimated in percentage change form, in order to recover predictions in level form, it is necessary to cumulate percentage changes from a base level for 1979Q4. The base level used was the actual price level for 1979 Q 4 . In the simulation, the sum of the coefficients on the per capita money growth variable was constrained to equal one. Imposition of this constraint affected the regression equation reported in Table I only very slightly. The predictions were made without use of the information contained in the autocorrelation of the error term.

Table III

\section{ERRORS IN PREDICTING CALENDAR YEAR INFLATION RATES}

\begin{tabular}{rrr|rrr} 
& \multicolumn{1}{c}{$M 1$ est. } & \multicolumn{1}{c}{ M2 est. } & & M1 est. & M2 est. \\
1952 & -2.2 & 1.2 & 1966 & .5 & .4 \\
1953 & -.18 & .3 & 1967 & -.6 & -1.0 \\
1954 & -.5 & .2 & 1968 & 1.0 & -.8 \\
1955 & .5 & 1.0 & 1969 & -1.3 & -.3 \\
1956 & .6 & .5 & 1970 & -1.2 & -.2 \\
1957 & .2 & .0 & 1971 & .1 & .0 \\
1958 & 1.0 & .3 & 1972 & -.5 & -.8 \\
1959 & .9 & -.4 & 1973 & -.5 & -1.3 \\
1960 & .2 & .4 & 1974 & 2.6 & 1.1 \\
1961 & -.3 & -.1 & 1975 & .2 & -1.1 \\
1962 & 1.4 & .8 & 1976 & 1.6 & .2 \\
1963 & -.7 & -1.6 & 1977 & 1.3 & 1.1 \\
1964 & -1.7 & -1.7 & 1978 & .2 & 1.4 \\
1965 & -.5 & -.9 & 1979 & .1 & 1.4 \\
\hline
\end{tabular}

Notes: Errors ore actual minus predicted values of calendar year inflation rates of the gross domestic purchases implicit price deflator. Calendar year inflation rates are calculated using successive fourth quarter levels. Predictions used in calculating the errors in columns labeled M1 est. and M2 est. ore made with regression equations estimated with M1 (Table I) and M2 (Table II), respectively, No use was made of the information contained in the positively correlated regression errors in predicting the price level. 
Table IV

\section{POST-SAMPLE SIMULATION RESULTS: PERCENTAGE ERROR IN PREDICTING THE PRICE LEVEL}

\begin{tabular}{lrr} 
& $\begin{array}{r}\text { Regression } \\
\text { Estimated } \\
\text { with M1 }\end{array}$ & $\begin{array}{c}\text { Regression } \\
\text { Estimated } \\
\text { with Old M2 }\end{array}$ \\
\hline 1980Q1 & .1 & - \\
1980Q2 & .4 & - \\
1980Q3 & .2 & - \\
$1980 Q 4$ & .1 & - \\
$1981 Q 1$ & .4 & .9 \\
$1981 Q 2$ & -.6 & -.6 \\
$1981 Q 3$ & -.6 & 0.1 \\
$1981 Q 4$ & .0 & .6 \\
$1982 Q 1$ & -1.1 & .2 \\
$1982 Q 2$ & 1.9 & -.8 \\
$1982 Q 3$ & -2.1 & .3 \\
$1982 Q 4$ & -3.8 & -1.5 \\
$1983 Q 1$ & -5.0 & -2.0 \\
$1983 Q 2$ & -6.3 & -2.4 \\
$1983 Q 3$ & -7.5 & -3.2 \\
$1983 Q 4$ & -8.6 & -3.6 \\
$1984 Q 1$ & -8.9 & -3.0 \\
$1984 Q 2$ & -9.6 & -3.4 \\
$1984 Q 3$ & -9.8 & -2.9 \\
\hline
\end{tabular}

Notes: Errors are calculated as the difference between the actual and predicted level, divided by the predicted level, of the implicit price deflator for gross domestic, purchases. The predicted values used in calculating the emors in column 1 were generated using the regression equation estimated with M1 and summarized in Table $I$. This regression was simulated out of sample with the M1 series. The predicted values used in calculating the errors in column 2 were generated using the regression equation estimated with old M2 and summarized in Table II. This regression was also simulated out of sample with the Ml series. No use was made of the positively autocorrelated regression errors, so the simulations are completely dynamic in character.

dicted price level exceeds the actual price level by an ever-increasing amount over the post-estimation, period. ${ }^{7}$ By 1984Q3, the predicted price level exceeds

\footnotetext{
${ }^{7}$ This fact casts doubt on an explanation for the rightward shift in the public's M1 demand function common in 1982. It was argued that the 1982 recession increased uncertainty and, consequently, increased the public's precautionary demand for M1. As measured by the M 1 demand function estimated from 1952Q1 to 1979Q4, the public's MI demand function continued to shift rightward after the recovery began in 1982Q4, however. According to the above explanation, the recovery, by reducing economic uncertainty, should have ended, and even reversed, the rightward shift begun in 1982.
}

the actual price level by about 10 percent. As measured by the money demand regression equation (1), this overprediction of the price level indicates a rightward shift in the public's M1 demand function.

If the Friedman/Schwartz hypothesis is correct that the phasing out of the prohibition of payment of interest on consumer demand deposits has caused M1 to come to resemble M2 as formerly defined, then the demand for M1 in the early 1980s can be understood as behaving like the demand for old M2 prior to the 1980s. In this spirit, regression equation (1), estimated with old M2 as shown in Table II, was simulated with M1 over the out-of-sample period 1981Q1 to $1984 \mathrm{Q} 3{ }^{8}$ The percentage error in predicting the price level is reported in the second column of Table IV. The predictions appear reasonably accurate. After about four years, the price level is over predicted by 2.9 percent.

Most of the error in predicting the price level over this period occurs in 1983. From 1982Q4 to 1983Q4, the predicted inflation rate exceeded the actual inflation rate by 2.1 percentage points. As revealed by Table III, the magnitude of the error exceeds the magnitude of the calendar year error produced from the within-sample simulations for all years for estimation with old M2, but is smaller for two years for estimation with M1. The error for 1983 may be related to the introduction in January 1983 of Super NOW accounts. The inflation rate, however, begins to be overpredicted in 1982Q4, rather than in 1983Q1. Alternatively, the historically high rates of growth of M1 in 1982Q4, 1983Q1, and 1983Q2 in combination with the severely depressed level of economic activity may have produced a transitory level of excess real balances, as measured by regression equation (1). ${ }^{9}$ This explanation is consistent with

\footnotetext{
${ }^{8}$ The out-of-sample simulation begins in 1981Q1 because of the assumption that it was the nationwide introduction of NOW accounts in 1981Q1 that caused the behavior of the public with respect to $M 1$, to come to resemble its former behavior with respect to old $M 2$. The estimated regression equation is modified slightly by constraining the coefficients to sum to one. No use is made of the information contained in the autocorrelated errors. In order to recover predictions in level form, percentage changes are cumulated from the actual 1980Q4 value of the price level.

${ }^{9}$ What is meant by the expression "excess real balances" is that some of the adjustment to the unusually high rates of growth of M1 was accounted for by variables other than those included in regression equation (1). In particular, individuals and businesses may have drawn down the level of trade credit that they ordinarily extend among themselves.
} 
the reduction in the overprediction of the price level that appears from Table IV to have started in 1984Q3.

If the Friedman/Schwartz hypothesis is valid, the recent inflation rate has been low relative to historically high rates of' growth of M1 in 1982 and 1983 only in part because of the increased demand for M1 due to a decrease in the cost of holding M1 caused by the fall in market rates and an increase in the own marginal rate of return on M1. More important influences in retarding inflation have been the lowering of the trend rate of decline in the demand for M1 and the increased income elasticity of demand for M1. This latter factor has combined with high rates of growth of real expenditure since 1982Q1 to keep the rate of inflation low relative to money growth. Also, the fact that the recent behavior of inflation is reasonably well predicted under the assumption that the public's behavior toward M1 since 1981Q1 resembles its former behavior toward old M2 suggests that there was a one-time change in the character of the M1 demand function in response to financial innovation, with this function approximately stable before and after the change.

An attempt to implement empirically the initial balance hypothesis was less successful. A shiftadjusted M1 series was constructed that begins in 1981Q1. A minimum balance requirement of $\$ 500$ and \$2500 was assumed for NOW accounts and Super NOWs, respectively. It was also assumed that all of the minimum balance requirements on these deposits is met by shifting funds from savings accounts. Shift-adjusted M1 was then constructed by subtracting from $\mathrm{M} 1$ an estimate of that part of NOW and Super NOW accounts represented by minimum balance requirements. Regression equation (1), estimated with M1 as shown in Table I, was then simulated from 1980Q1 through 1984Q3 with this shift-adjusted M1 series. The overprediction of the price level of about 10 percent shown in column 1 of Table IV was reduced only about three percentage points. (An attempt to use a cost variable in the regression that accounted for the increase in the own rate of return on M1 that occurred due to the explicit payment of interest on NOWs and Super NOWs helped only marginally.) The initial balance hypothesis thus requires that consumers, when opening new OCD accounts, transfer into these accounts an amount from savings deposits that exceeds the minimum balance requirements. This latter assumption appears plausible.

The results presented above are summarized in Charts 1 and 2. Both charts display actual, annualized quarterly inflation rates from 1952Q1 to 1984Q3. In Chart 1 , this series is predicted by the regression equation fitted with M1 (Table I) and simulated

Chart 1

\section{ACTUAL AND PREDICTED INFLATION: PREDICTED INFLATION FROM REGRESSION FITTED WITH M1}

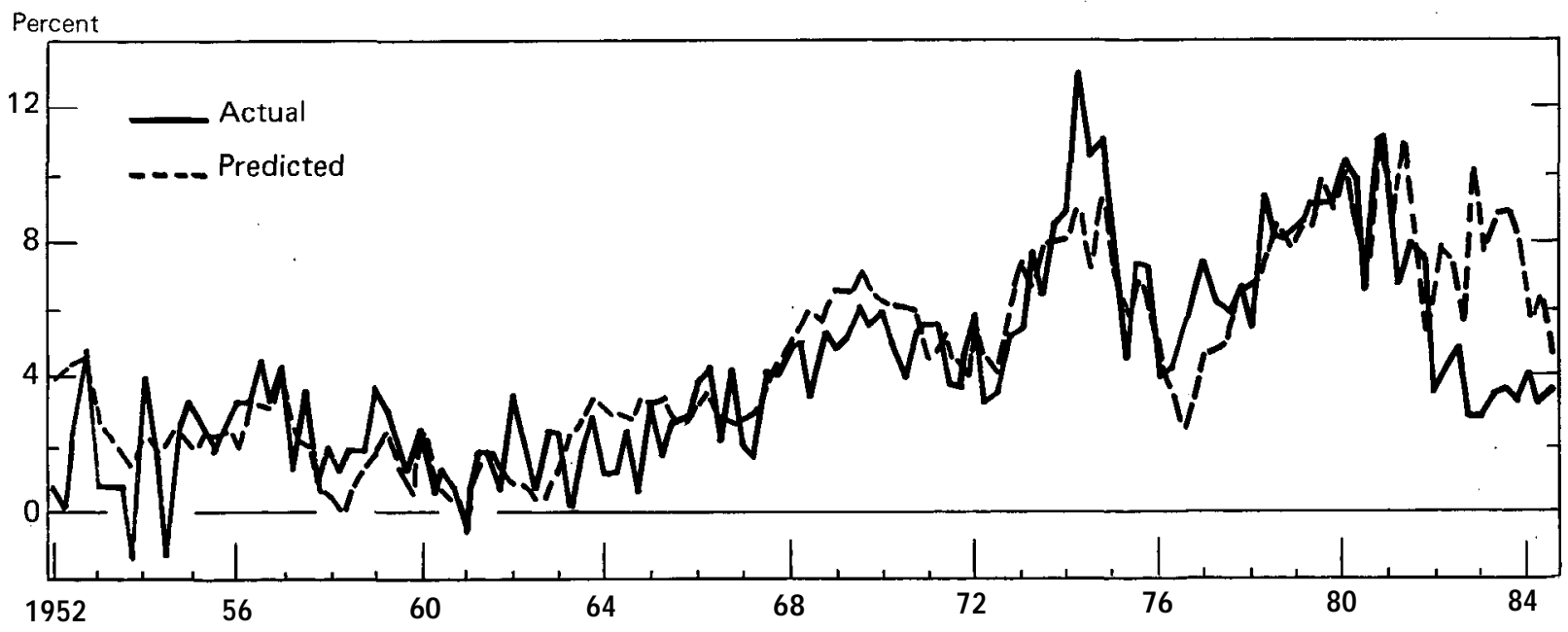

Notes: Solid line plots the actual, annualized, quarterly percentage growth rates, continuously compounded, of the implicit gross domestic purchases deflator. The dotted line plots predicted values from a regression equation fitted with M1. From 1952Q1 to 1979Q4, predictions are within sample; from 1980Q1 to 1984Q3, they are out of sample. 
with M1. ${ }^{10}$ From 1952Q1 to 1979 Q4, these predictions are within sample; and from 1980Q1 to 1984Q3, they are out of sample. The within-sample predictions appear reasonably accurate. ${ }^{11}$ Beginning in 1982, however, inflation is overpredicted to a significant degree. This overprediction indicates a rightward shift in the public's M1 demand function, at least as measured by regression equation (1).

In Chart 2, the quarterly inflation rate is predicted

${ }^{10}$ The estimated regression equation is modified slightly by constraining the coefficients on money to sum to one. Predictions do not make use of the information contained in the autocorrelated errors.

${ }^{11}$ From 1955 through 1960 and from 1974 through 1978 inflation is somewhat underpredicted. This underprediction indicates a moderate leftward shift in the MI demand function. The reduction in MI demand may have been caused, in the first instance, by the significant increase in competition for consumer deposits associated with the increase in the importance of the thrift industry. The reduction in $\mathrm{M} 1$ demand may have been caused, in the second instance, by the increase in the importance of cash management techniques prompted by the high level of nominal rates on interest in the 1970s. Dummy variables were incorporated in regression equation (1) in order to estimate the magnitude of these shifts (but were not used in any of the results reported in the paper). The magnitude of these shifts is small relative to changes in the rate of growth of M1. Although the public's MI demand function did exhibit shifts between 1952 and 1979, the moderate magnitude of these shifts relative to changes in the rate of growth of M1 suggests the usefulness of the view of inflation as a monetary phenomenon. by the regression equation fitted with M2 (Table II). ${ }^{2}$ From 1952 Q1 to 1979 Q4, these predictions are within sample; and from 1981Q1 to 1984Q3, they are out of sample. Within sample, the regression was simulated with M2, but out of sample, it was simulated with M1. The within-sample predictions are reasonably accurate. In the out-of-sample period, the downward trend in the inflation rate that begins in 1981 is predicted, although inflation is overpredicted in 1983.

\section{Predicting Inflation}

The Friedman/Schwartz hypothesis implies that the deregulation of the financial system in the early 1980 s has altered permanently the characteristics of M1. The initial balance hypothesis implies that the inclusion in M1 of instruments suitable for consumer saving has caused only a onetime rightward shift in the M1 demand function; for example, the constant term in the money demand regression equation (1) has experienced. a temporary reduction. After the initial adjustment by the public to financial deregu-

\footnotetext{
${ }^{12}$ See note 10 above.
}

ACTUAL AND PREDICTED INFLATION: PREDICTED INFLATION FROM REGRESSION FITTED WITH OLD M2

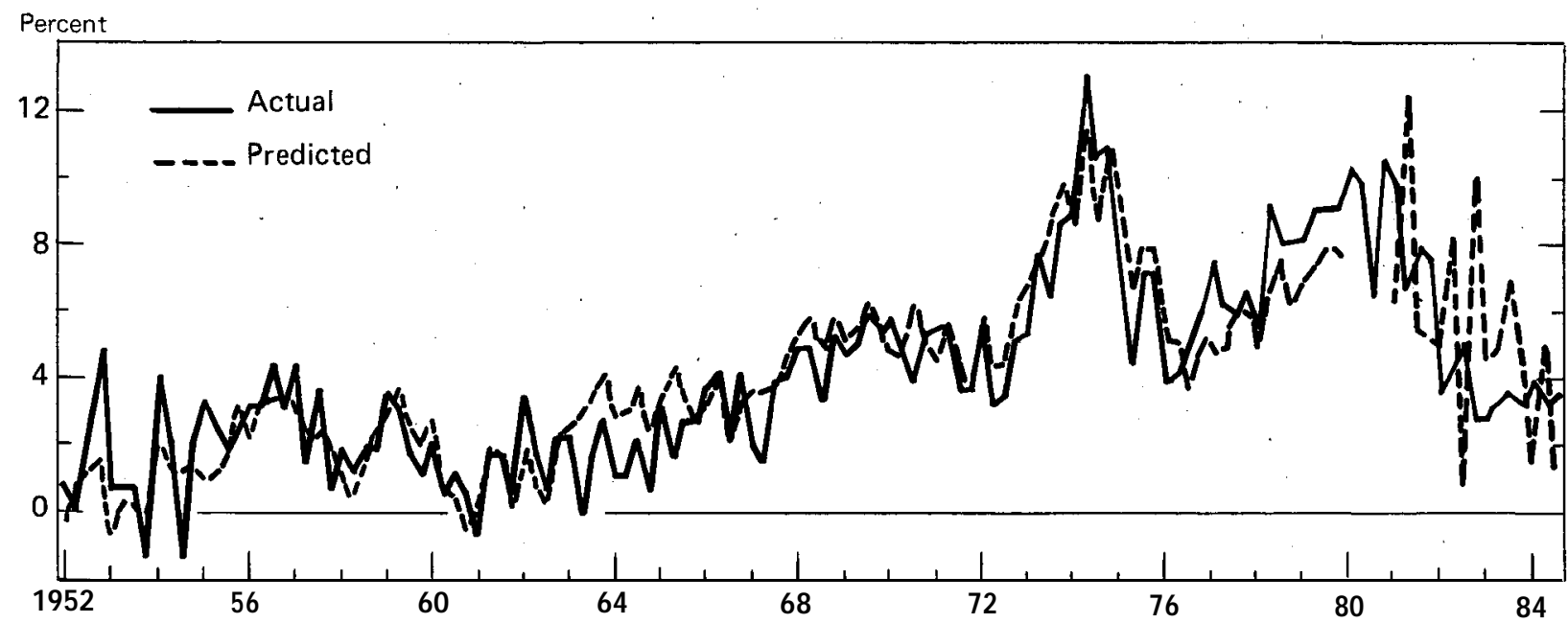

Notes: Solid line plots the actual, annualized, quarterly percentage growth rates, continuously compounded, of the implicit gross domestic purchases deflator. The dotted line plots predicted values from a regression equation fitted with old M2. From 1952Q1 to 1979Q4, the simulations are within sample and are performed with old M2. From 1981Q1 to 1984Q3, the simulations are out of sample and are performed with M1. 
lation, the M1 demand function will again exhibit its pre-1981 characteristics. Only with the passage of time can these two competing hypotheses be tested. Two sets of predictions of future inflation are made below in order to aid in discriminating between these hypotheses in 1985.

First, the inflation rate is predicted for 1984Q4 and for 1985 under the assumption that the public's M1 demand function will henceforth reassume its pre-1981 character. Specifically, inflation is predicted by simulating with M1 the regression equation estimated with M1 through 1979Q4 (reported in Table I ) ${ }^{13}$ Second, the inflation rate is predicted under the assumption that the characteristics of M1 as currently defined will resemble those of M2 as formerly defined. Specifically, inflation is predicted by simulating with M1 the regression equation estimated with old M2 through 1979Q4 (reported in Table II). ${ }^{14}$

Predictions of future inflation are conditional upon the future values assumed for the pertinent explanatory variables. It is assumed that the paper rate will not change. It is assumed that for 1984Q4 through 1985Q4 per capita real gross domestic expenditure will grow at an annualized rate of 2 percent. (This figure is virtually the historical growth rate for this series between the two business cycle troughs 1949Q4 and 1982Q4.) Also, it is assumed that M1 will grow at the midpoint of its current four-quarter target range for 1984Q4, 6 percent, and at the midpoint of its tentative target range for 1985, 5.5 percent. Over the decade from 1974 through 1983, the rate of growth of population was virtually one percent per year. Under the assumption that population will continue to grow at this rate, a rate of growth of 5 percent is assumed for per capita M1 for 1984Q4, and a rate of growth of 4.5 percent for 1985 .

The two sets of simulations described above are reported in Table $\mathrm{V}$. They are, of course, conditional predictions and will need to be adjusted in light of the actual behavior of the explanatory variables like per capita growth in M1. The important point is that the predictions diverge. By the end of 1985, the predicted rate of inflation is three percentage points higher under the assumption that the public's M1 demand function has reverted to its pre-1981 char-

\footnotetext{
${ }^{13}$ The coefficients on money are constrained to sum to one.

${ }^{14}$ See note 13 above.
}

acter than under the assumption that it has come to resemble the former old M2 function. ${ }^{15}$ The behavior of the actual inflation rate will, therefore, offer evidence on whether the current characteristics of the M1 demand function have reverted to the pre-1981 characteristics or have changed permanently to reflect the inclusion in M1 of assets with a savings, as well as a transactions, property. Assuming that the Federal Reserve System achieves a rate of growth of M1 equal to the midpoint of its target range, and that the rate at which new OCDs are introduced subsides,. an inflation rate in 1985 around six percent will favor the initial balance hypothesis, while an inflation rate around three percent will favor the Friedman/ Schwartz hypothesis. ${ }^{16}$

\begin{abstract}
${ }^{15}$ The high rates of real expenditure through 198403 depress the predicted inflation rates. Because the coefficients on real expenditure in the regression estimated with $\mathrm{M} 2$ are relatively large in magnitude, this depressing effect is larger for predictions made with this regression. Also, the depressing effects last longer for predictions made with this regression because the distributed lag relationship between inflation and growth in real expenditure is relatively long.

${ }^{16} \mathrm{~N}$ ote that if the initial balance hypothesis is correct, inflation should actually be somewhat higher than six percent. In January 1985, the legal minimum balance requirement on Super NOWs is scheduled to be reduced from $\$ 2,500$ to $\$ 1,000$. According to the logic of this hypothesis, this reduction should cause a leftward shift in the public's M1 demand function as funds previously used to satisfy minimum balance requirements are moved back into savings instruments. For a given rate of growth of $M 1$, the inflation rate should be temporarily higher.
\end{abstract}

Table V

\section{PREDICTIONS OF FUTURE INFLATION RATES}

\begin{tabular}{ccc} 
& $\begin{array}{c}\text { Regression } \\
\text { Estimated } \\
\text { with M1 }\end{array}$ & $\begin{array}{c}\text { Regression } \\
\text { Estimated } \\
\text { with Old M2 }\end{array}$ \\
\cline { 2 - 3 } $1984 Q 4$ & 4.5 & 1.0 \\
$1985 Q 1$ & 5.0 & 2.4 \\
$1985 Q 2$ & 4.8 & 2.3 \\
$1985 Q 3$ & 5.6 & 2.7 \\
$1985 Q 4$ & 5.7 & 2.7 \\
\hline
\end{tabular}

Notes: Predictions in column 1 are mode with regression equation (1) estimated with M1 from 1952Q1 to $1979 Q 4$ and simulated with M1. Predictions in column 2 are made with regression equation (1) estimated with old M2 from 1952Q1 to 1979Q4 and simulated with M1. 


\section{An Alternative Explanation of M1 Demand}

The exposition in this article has concentrated on two alternative explanations for the recent behavior of M1 demand because of the author's belief that the data on M1 demand that will become available in 1985 will allow one to discriminate between these explanations. In this section; a third explanation for M1 demand is discussed. Discrimination between this last explanation and alternative explanations of M1 demand will require additional observations for periods over which interest rates move significantly. The strength in M1 demand in 1982 and 1983 could be explained by a rise in the interest elasticity of the demand for real M1 balances (Brayton 1983) in combination with the significant drop in the level of market rates of interest relative to the own rate on OCDs (Judd 1983 and Judd and Motley 1984). The rise in the interest elasticity of M1 demand could have been caused by the appearance of substitutes for M1 like money market mutual funds and money market deposit accounts (Dotsey 1981/1982). An explanation of the behavior of M1 demand in this spirit requires that regression equation (1) be modified in order to take account of the own rate of return on M1. Construction of this latter variable is discussed below.

In the case of consumer demand deposits, as opposed to corporate demand deposits, circumvention of the prohibition of the payment of interest on demand deposits is a cumbrous procedure. Implicit interest has been paid on consumer demand deposits by offering check clearing services below cost. This arrangement allows consumer demand deposits to offer a positive average return. Consumers can increase the return yielded on their demand deposit balances by using them more intensively, that is, by writing a greater number of checks for a given average balance. They can not, however, increase the return yielded by- their deposits by holding a larger balance. Specifically, while the implicit average yield on consumer demand deposits is positive, the implicit marginal yield is zero (Offenbacher 1982). The introduction of explicit payment of interest on OCDs has caused the marginal own yield on these deposits to become positive. A marginal own rate of return on M1 could be constructed as a weighted average of the marginal own rates of return of the various components of M1. The own rate of return on consumer demand deposits and on currency would be zero; the own rate of return on OCDs would be an average of the explicit rates paid on these deposits; and the own rate of return on corporate demand deposits would be, a market rate of interest reduced by a factor that accounts for the tax levied by non-interest-bearing required reserves. ${ }^{17}$

A cost variable that would allow for the maximum effect on the demand for money in 1982 and 1983 of the fall in market rates and the increase in the own rate on $\mathrm{M} 1$ is the spread between a short-term interest rate, for example, the rate of interest on 3 -month Treasury bills, and the own rate of return on M1 (Brayton 1983). This spread measures the cost of holding M1 balances, that. is; the cost of utilizing the monetary services rendered by $\mathrm{M} 1{ }^{18}$ The hypothesis of this section builds on the fact that the percentage decline in this spread exceeded the percentage decline in market rates and also on the conjecture that the magnitude of the coefficient on such a variable increased in the 1980s. The increased demand for M1 in 1982 and 1983 is, then, accounted for by the fall in market rates of interest, both absolutely and relative to the own rate of return on M1. This fall, in combination with a heightened sensitivity of M1 demand to spreads between market rates and own rates on M1, caused an increase in M1 demand. Evidence useful for evaluating the above hypothesis will become available when major movements in the cost of holding M1, as measured by the cost variable described above, occur. At such a time, a money demand regression equation of the kind estimated in Table I, that is, one exhibiting only minimal interestrate elasticity, will produce prediction errors for real M1 balances that are negatively correlated with the movement in market rates.

\section{Implications for Policy}

The character of the public's M1 demand function possesses important implications for monetary policy. An illustration of this fact concerns the value of the noninflationary trend rate of growth of M1. If the Friedman/Schwartz hypothesis is correct, the decrease in the trend rate of decline in the demand for M1 and the increase in the income elasticity of de-

\footnotetext{
${ }^{17}$ The division of demand deposits between corporate and consumer deposits, necessary in order to construct the own rate of return on $\mathrm{M} 1$ as suggested, is only available beginning in the 1970s in the Board of Governors Demand Deposit Ownership Survey. For this reason, it was not possible to incorporate an own rate of return variable into the money demand regression equation (1), estimation of which carried out for the period beginning in $1952 \mathrm{Q} 1$.

${ }^{18}$ In principle, a long-term rate of interest minus the own rate of return on $\mathrm{M} 1$ should enter also. Given the correlation in the movement of long and short rates, entering both variables would not add significant explanatory power to the right-hand variables in a regression equation.
} 
mand for M1 will lower the inflation rate associated with any given rate of growth of M1. The noninflationary trend rate of growth of M1 can be solved for from regression equation (1) by determining what rate of growth of money is compatible with zero inflation, given estimates for the secular behavior of the interest rate, real expenditure, and population growth, and given the relevant parameter estimates. ${ }^{19}$ If the Friedman/Schwartz hypothesis is correct that M1 now possesses the characteristics of old M2, the

\footnotetext{
${ }^{19}$ It is assumed here that there will be no secular change in the level of the interest rate. It is assumed that the secular rate of growth of real per capita gross domestic expenditure will be two percent, the virtual actual average between the business cycle troughs in 194904 and 1982Q4. Also, it is assumed that population growth will be one percent per year. the virtual-actual average over the decade from-1974 to 1983 . With respect to parameter estimates, it is assumed that the sum of the coefficients on money is one. The other key parameter estimates are the secular rate of decline in the demand for $M 1$ and the elasticity of the demand for Ml with respect to the real expenditure of the public. These estimates are taken to be the constant term (.76) and the sum of the estimated coefficients on the real expenditure term (-.94) that are reported for estimation of (1) in Table II (again under the assumption that the demand function for $\mathrm{M} 1$ now resembles that for old $\mathrm{M} 2$ ).
}

noninflationary rate of growth of M1 rose after 1981 about two percentage points to a current level slightly in excess of two percent per year.

\section{Summary}

Two competing hypotheses have been exposited in this article concerning the nature of the public's M1 demand function in the 1980s. They were chosen because of the likelihood that observations on the behavior of the public's demand for real M1 balances in 1985 will offer evidence on their validity. The first hypothesis, labeled the Friedman/Schwartz hypothesis, predicts a lower rate of inflation in 1985 than the second hypothesis, labeled the initial balance hypothesis. A third hypothesis was also exposited. Evidence relevant for assessing its validity will become available in 1985 if a major movement in market rates of interest occurs. Knowledge of the nature of the public's M1 demand function is important in order to assess the impact on the expenditure of the public of a particular rate of growth in M1. This knowledge is also important in order to determine the value of the noninflationary rate of growth of M1.

\section{References}

Brayton, Flint; Terry Farr; and Richard Porter. "Alternative Money Demand Specifications and Recent Growth in M1." Board of Governors of the Federal Reserve System (May 23, 1983), mimeographed.

Coats, Warren L., Jr. "Modeling the Short-Run Demand for Money with Exogenous Supply." Economic Inquiry (A pril 1982), pp. 222-239.

Cook, Timothy Q., and Timothy D. Rowe. "What Are OCDs." Federal Reserve Bank of Richmond (November 1984), mimeographed.

Dotsey, Michael ; Steven Englander; and John C. Partlan. "Money Market Mutual Funds and Monetary Control." Quarterly Review, Federal Reserve Bank of New York (Winter 1981/1982), pp. 9-17.

Fama, Eugene F. "Inflation, Output, and Money." Journal of Business (April 1982), pp. 201-231.

Harberger, Arnold C. "The Dynamics of Inflation in Chile" in M easurement in Economics. Stanford, CA: Stanford University Press, 1963.
Hetzel, Robert L. "Estimating Money Demand Functions." Journal of M oney, Credit, and Banking (May 1984), pp. 185-193.

Judd, John P. "The Recent Decline in Velocity: Instability in Money Demand or Inflation?" Economic Review, Federal Reserve Bank of San Francisco (Spring 1983), pp. 12-19.

and Brian Motley. "The 'Great Velocity
Decline' of 1982-83: A Comparative A nalysis of
M 1 and M2." E conomic Review, Federal Reserve
Bank of San Francisco (Summer 1984), pp. 56-68.
Laidler, David. M on etarist Perspective. Cambridge :
Harvard University Press, 1982.
Offenbacher, Edward; Paul Spindt; and Clif Wilson.
"Recent. Behavior of the Divisia Monetary Aggre-
gates." Board of Governors of the Federal Reserve
System (A pril 9, 1982), mimeographed.

Schwartz, Anna J. “Monetary Issues." N BER Reporter' (Winter 1983/4), pp. 14-18. 